\title{
caulgarraus
}

\section{IN VITRO AND IN VIVO EFFECTS OF PDGF-BB DELIVERY STRATEGIES ON TENDON HEALING: A REVIEW.}

\author{
O. Evrova ${ }^{1,2}$ and J. Buschmann ${ }^{1, *}$ \\ ${ }^{1}$ Division of Plastic Surgery and Hand Surgery, University Hospital Zurich, Zurich, Switzerland \\ ${ }^{2}$ Laboratory of Applied Mechanobiology, ETH Zurich, Zurich, Switzerland
}

\begin{abstract}
To promote and support tendon healing, one viable strategy is the use or administration of growth factors at the wound/rupture site. Platelet derived growth factor-BB (PDGF-BB), together with other growth factors, is secreted by platelets after injury. PDGF-BB promotes mitogenesis and angiogenesis, which could accelerate tendon healing. Therefore, in vitro studies with PDGF-BB have been performed to determine its effect on tenocytes and tenoblasts. Moreover, accurate and sophisticated drug delivery devices, aiming for a sustained release of PDGF-BB, have been developed, either by using heparin-binding and fibrin-based matrices or different electrospinning techniques.

In this review, the structure and composition, as well as the healing process of tendons, are described. Part A deals with in vitro studies. They focus on the multiple effects evoked by PDGF-BB on the cellular level. Moreover, they address strategies for the sustained delivery of PDGF-BB. Part B focuses on animal models used to test different delivery strategies for PDGF-BB, in the context of tendon reconstruction. These studies showed that dosage and timing of PDGF-BB application are the most important factors for deciding which delivery device should be applied for a specific tendon laceration.
\end{abstract}

Keywords: PDGF-BB, tendon healing, heparin, electrospinning, biomechanics.

* Address for correspondence: Dr Johanna Buschmann, University Hospital Zurich, ZKF, Division of Plastic Surgery and Hand Surgery, Sternwartstrasse 14, 8091 Zurich, Switzerland

Telephone: +41 $442559895 \quad$ Fax: +41 442555047 Email: johanna.buschmann@usz.ch

\section{Introduction}

The healing of acutely injured tendons is a lengthy process, due to the inherent characteristics of these connective tissues. A poor vascular network and cells with low metabolic rate add to the poor intrinsic healing capacities andlimited regenerative potential of tendons. Often, the healing process is accompanied by development of a scar tissue next to properly regenerated tissue (Galatz et al., 2015). The fibrous scar tissue has inferior properties compared to native tissue, resulting in functional and mechanical insufficiencies (Elliot and Giesen, 2013a). Biological therapies may help to overcome these problems. One approach, investigated to support tendon repair both in vitro and in vivo, is the application of growth factors (Bissell et al., 2014; Hsu and Chang, 2004), including platelet-derived growth factor-BB (PDGF-BB) (Hee et al., 2012).

PDGF-BB is part of the PDGF growth factor family, which includes four isoforms (A, B, C and D) (Andrae et al., 2008). The PDGF-BB dimer - the mostly investigated isoform - is the only one that can bind to all three different surface PDGF receptors (PDGFRs) and trigger different signalling cascades, thus being called the universal isoform of PDGF. Compared to other growth factors, PDGF-BB has a well-established safety profile, approved by the Food and Drug Administration (FDA) (Borena et al., 2015), and formulations supporting wound healing in foot ulcers, as well as, bone regeneration are on the market [Regranex Gel ${ }^{\circledR}$ (Smith\&Nephew, London, UK) and GEM 21S ${ }^{\circledR}$ (Luitpold, Pharmaceuticals, Shirley, NY, USA)] (Howard et al., 2014; Ma et al., 2015). In chronic foot ulcers, topical application of rhPDGF led to a significant increase (by $43 \%$ ) in the incidence of complete wound closure and decrease in healing time (by $32 \%$ ) over placebo-controlled wound care, resulting in the FDA approval of Regranex Gel ${ }^{\circledR}$ (Wieman et al., 1998). The effect of PDGF-BB in supporting osteogenic differentiation has been shown in an in vitro study with MG63 cells (Vahabi et al., 2016). In addition, positive clinical results for GEM $21 S^{\circledR}$ were reported in regenerative 
periodontal surgery (Singh and Suresh, 2012). Moreover, platelet-rich plasma (PRP), blood plasma enriched with platelets, which release different growth factors (including PDGF-BB) upon activation by thrombin, has also been reported to be beneficial in a clinical setting [see reviews about PRP use in patellar tendinopathy (Jeong et al., 2014) and PRP use in medical collateral ligament injuries (Andia and Maffulli, 2015)]. Injection of PRP has been shown to be superior to shock wave therapy when treating jumper's knee (patellar tendon or quadriceps tendon) (Vetrano et al., 2013) and to reduce donor site morbidity in patellar tendons (de Almeida et al., 2012). However, one big disadvantage of PRP is its variability in composition, due to different preparation protocols and patient differences, resulting in different effects with regard to growth factor composition and release (Marques et al., 2015; Schaer et al., 2015). Hence, mixed outcomes in clinical settings resulted after PRP application (Castillo et al., 2011; de Vos et al., 2010; Eppley et al., 2004; Foster et al., 2009; Kevy and Jacobson, 2004; Nikolidakis and Jansen, 2008). Therefore, a defined mixture of growth-factors or one single growth factor like PDGF$\mathrm{BB}$ delivered in a controlled way present a good alternative for eliminating variability in treatment outcomes.
The functions of PDGF during tendon healing are manifold. After blood clot formation, platelets (thrombocytes) release a series of growth factors that interact with each other (Anitua et al., 2007). PDGF attracts inflammatory cells, such as neutrophils and macrophages, responsible for the breakdown and phagocytosis of the debris (Deuel et al., 1982; Inaba et al., 1993; Tzeng et al., 1985). Also, PDGF attracts tenocytes and fibroblasts that migrate to the wound site and start synthesising extracellular matrix components, including collagen (Banes et al., 1995; Siegbahn et al., 1990; Spindler et al., 1995; Thomopoulos et al., 2005).

When PDGF-BB is applied as a biological therapy, the time point of application and the dosage significantly impact its effectiveness. As the endogenous release of PDGF-BB is during the inflammatory and early proliferative phase (Chen et al., 2008; Gulotta and Rodeo, 2009; Wuergler-Hauri et al., 2007), it should be administered within the first two weeks after injury, at best using a delivery method that allows a controlled and sustained release. So far, clinical use of PDGF-BB in the tendon repair field has not been reported, with the main issue represented by its administration, i.e. providing a reliable delivery system that will allow for a sustained delivery of bioactive PDGF-BB at the injured site.



Fig. 1. General overview of the tendon healing process. After injury, several different, overlapping phases [inflammatory, reparative (proliferative), remodelling and later modelling phase] comprise the process of tendon healing, each one lasting for a shorter (hours) or longer (weeks) time period and marked with specific molecular, cellular and tissue changes. The length of each phase can differ in different species. The initial two phases (within 1-2 weeks post-injury) would be the most suitable time for the application of a construct delivering bioactive PDGF at the site of repair (Docheva et al., 2015; Molloy et al., 2003; Sharma and Maffulli, 2006). 


\section{Materials and Methods}

Approximately $60 \%$ of the papers mentioned in this review (total number of papers included in this review: 175) were found by a search in the Web of Knowledge/Web of Science/Google Scholar databases using the key words "tendon AND PDGF OR platelet derived growth factor"; "tenocyte AND PDGF OR platelet derived growth factor"; "PDGF AND sustained delivery"; "PDGF AND electrospinning" (the search was performed during the period of February-August 2016 and only literature written in English was reviewed). The remaining $40 \%$ were cited in the references found within this search; with the exception of some very recent papers. The reviewed literature was published from 1978 to 2016 . Original research papers, communications, review papers, as well as book chapters, were included. We focused on PDGF-BB administration to lacerated tendons, either by single bolus injections or released in a sustained manner from a delivery device. Moreover, full transections of tendons, partial lacerations and tendinopathy animal models, such as collagenaseinduced tendinopathy, were included and the effects of PDGF-BB on the healing pattern were discussed. This review is divided into two main parts (A and $B$ ): in vitro and in vivo preclinical experiments.

\section{Composition and healing of tendons}

Tendons are constituted of fibres comprised of crosslinked collagen fibrils. Several different cell populations reside between chains of these long and parallel fibrils, including tenocytes (Lui, 2013), their precursor cells are called tenoblasts and tendon stem/progenitor cells (Bi et al., 2007; Kannus, 2000). Tenocytes, spindle-shaped and elongated, are the most numerous cell population and they are responsible for the formation/turnover of extracellular matrix, assembly of early collagen fibres and facilitation of collagen network adaptation to external stimuli (Milz et al., 2009). Tenoblasts, on the other hand, can vary in size and shape and are considered to be responsible for matrix (tissue) remodelling (Chuen et al., 2004). Tendon stem/ progenitor cells have been recently discovered and their capacity to differentiate into bone, cartilage or fat has been observed (Bi et al., 2007), as well as, the expression of certain stem cells markers (Oct4 and SSEA4 among others) (Lui and Chan, 2011; Zhang and Wang, 2010b). The percentage of tendon stem/ progenitor cells depends on age, species and type of tendon: younger specimens contain a higher percentage of tendon stem/progenitor cells (Zhou et al., 2010) and the functional fitness of the cells is higher when compared to aged specimens (Spindler et al., 1995).

The cell population, present within tendons, synthesises their necessary extracellular components, mainly collagens, glycosaminoglycans (GAGs), proteoglycans and elastin, and the composition varies slightly between tendons found in different locations of the body. Collagen fibres serve to maintain the tissue architecture, transmission and absorption of load and prevention of damage during mechanical stress (Pins et al., 1997). Collagen type I (Col I) is the major extracellular matrix (ECM) constituent, roughly $65-80 \%$ of the tendon dry mass (Kannus, 2000). Collagen type III (Col III) is the second most abundant collagen molecule and, although restricted to tendon sheets, it is the first collagen produced during tendon healing (Fig. 1) and is present in larger amounts in pathological tendons (Riley, 2004). Other collagen types in tendons include collagen type V, VI, XII, XIV and XV (Docheva et al., 2015). In addition, elastic fibres composed of elastin and fibrillin are broadly distributed throughout tendons, with longitudinal localisation around cells and transversal localisation between collagen fascicles (Giusti and Pepe, 2016; Grant et al., 2013; Kielty et al., 2002). They allow tendon's extendibility and elasticity and are thought to play a role in the reestablishment of the crimp pattern of collagen fibres after tendon stretching (Butler et al., 1978).

Even though mature tendons are characterised by low cellular density $(\sim 20 \%$ of the total tissue volume; Nordin et al., 2001), the cell population within the tendon is immediately affected upon tendon injury/damage. The healing process of tendons follows several phases, each characterised by different molecular elements and mechanisms (Fig. 1). Immediately after injury, a mix of cytokines and growth factors is released from the platelets and inflammatory cells,-such as macrophages, monocytes and neutrophils, attracted to the wound site (Fig. 2) and produce tumour necrosis factor (TNF) or growth factors involved in neovascularisation, such as vascular endothelial growth factor (VEGF), fibroblast growth factor (FGF) and PDGF (Chazaud, 2014; Lynch et al., 1987). During healing, fibrin clot formation serves as a provisional scaffold, releasing a variety of growth factors, aiding the healing process. However, occasionally, this provisional scaffold is missing, as in the healing of anterior cruciate ligaments (ACL), and has been pointed out as a reason why the ACL does not have innate healing capacity (Murray et al., 2000; Murray et al., 2007; Murray and Fleming, 2013). The inflammatory phase takes place within the first hours after injury. It is followed by a proliferative, i.e. reparative, phase during which, fibroblasts, recruited from the tendon sheath and tendon, proliferate as a result of the mix of growth factors [ transforming growth factor beta (TGF $\beta$ ), FGF, Insulin-like growth factor 1 (IGF-1), PDGF and VEGF] produced at the wound site, and afterwards start synthesising ECM components, like collagen - predominantly type III and proteoglycans. Angiogenesis, even though it may be thought as haphazard, is essential and beneficial, since lack of blood supply can impair the healing 
process. Later, this transient capillary network has to retract so that the healing process can progress properly (Fenwick et al., 2002).

In the next stage, remodelling of the tissue takes place by decrease of the cellular and vascular content and subsequent increase in deposition of collagen type I. Water content and glycosaminoglycan amounts stay larger in this phase (Oakes, 2008). In the modelling phase (consolidation + maturation), disorganised and randomly oriented collagen fibres are reorganised and healing tissue is reshaped and resized. During consolidation, the tissue changes from cellular to fibrous, synthesis of collagen type I still takes place and the collagen fibres become aligned in the direction of the stress (Hooley and Cohen, 1979). In the final stage, collagen fibril crosslinking is increased and the tissue changes gradually from fibrous to scar-like tendon tissue. The functionality after the healing is not the same as the one of a native tendon, due to structural aspects, i.e. alignment of collagen fibres, level of collagen cross-linking and natural crimp of collagen fibres differ from the native tendon (Connizzo et al., 2013). In order to re-establish this aspect, proper tissue organisation, i.e. collagen fibre organisation, needs to be addressed and improved. Changes in elastic fibres during tendon healing have not been studied in detail yet, but initial evidence suggests that there is an increase in fibrillin-1 synthesis accompanied with a small increase in elastin production (Thakkar et al., 2014). How this translates directly to the functional aspects of healed tendons is not clear yet. With regards to the cellular mechanism involved in tendon healing, it is believed that two mechanisms act together, intrinsic healing and extrinsic healing (Fenwick et al., 2002; Kajikawa et al., 2007). Initially, fibroblasts and inflammatory cells, from the tendon periphery and blood, are activated and migrate to the injury site, thus contributing to cell infiltration/ adhesion formation and constituting the extrinsic mechanism (Beredjiklian, 2003). Later, the intrinsic mechanism takes place with cells from the endotenon being activated and migrating to the injury site, where they proliferate, synthesise ECM and play a role in its reorganisation (James et al., 2008; Lin et al., 2004). Indeed, one study has shown that the healing is a biphasic pattern (Kajikawa et al., 2007).

The development of scar-like tendon tissue during healing leads to inferior mechanical, structural and biological properties, compared to non-injured tendons. For this reason, it has been proposed that application of bioactive constructs or injectable systems should aim at stimulating the intrinsic and suppressing the extrinsic healing mechanism to get improved restoration of the mechanical and functional properties of the healed tendons (Lomas

\section{Upon injury}


(Thrombocytes)

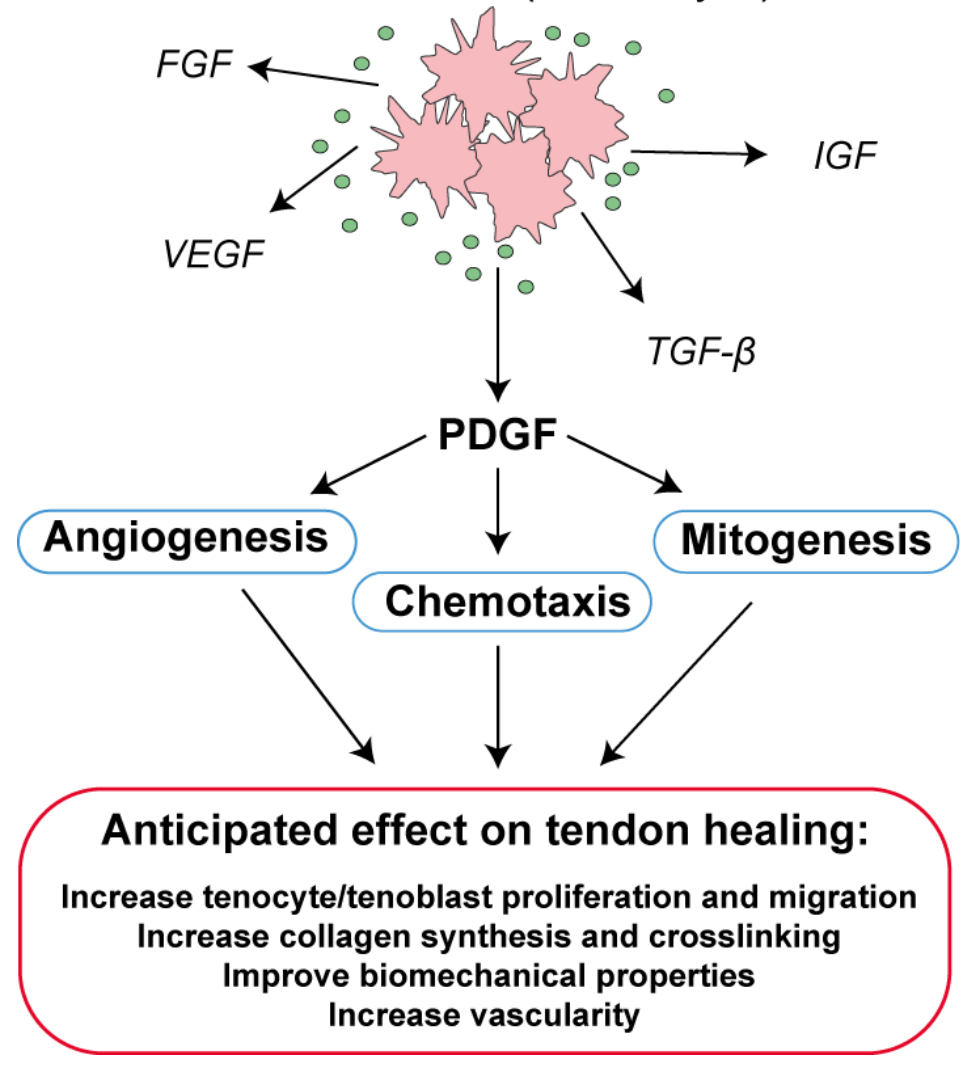

Fig. 2. Release and mechanism of action of PDGF after tendon injury. After an acute tendon injury, growth factors, such as transforming growth factor- $\beta$ (TGF- $\beta$ ), vascular endothelial growth factor (VEGF), fibroblast growth factor (FGF), platelet derived growth factor (PDGF) and insulin like growth factor (IGF), are released from $\alpha$-granules secreted by platelets at the wound site. PDGF upregulates VEGF and expression of integrins involved in smooth muscle cell migration, thus promoting angiogenesis. PDGF has chemotactic and mitogenic effects on neutrophils, macrophages and phagocytes, responsible for breakdown and cleaning of tissue debris, as well as, on tenocytes that enter the wound site to regenerate the damaged tissue. As a result, delivery of PDGF at the wound site can positively affect collagen deposition and crosslinking, biomechanical properties of a healing tendon, and also increase transient vascularisation by providing extrinsic factors for tendon repair. 
et al., 2015; Tang, 2005). However, achieving good tendon regeneration, with proper tissue organisation and without any trans-differentiation of tenocytes into fibrocartilaginous or bone tissue (de Mos et al., 2007; Zhang and Wang, 2010a), allowing proper tendon function and mechanical properties, still represents a major challenge when considering any biological strategy for tendon repair.

\section{PDGF-BB is predominantly expressed during tendon healing}

The pathways regulating normal tendon development are not completely understood, but it has been shown that FGF, TGF $\beta$ and growth differentiation factor (GDF) signalling regulate different aspects of tenogenesis. So far, PDGF involvement in tendon development has not been described. TGF $\beta$ (specifically TGF $32 / 3$ ) and FGF (specifically FGF4 and FGF8) signalling are shown to play a role in collagen expression/synthesis during development and in adult life (Brent and Tabin, 2004; Kuo et al., 2008; Mikic et al., 2006; Paxton et al., 2012; Yun et al., 2010). Tendon differentiation is mediated through the Smad signalling pathway of TGF $\beta$ (Lorda-Diez et al., 2009; Pryce et al., 2009). Disruption of FGF and TGF $\beta$ signalling leads to expression inhibition of the tendon associated transcription factor scleraxis (Scx) (Brent and Tabin, 2004; Brent et al., 2005; EdomVovard et al., 2002; Pryce et al., 2009). Scx is a basic helix-loop-helix transcription factor, involved in regulating expression of other tenogenic markers such as tenascin-C, tenomodulin, Mohawk and type I collagen. It is expressed in tendon progenitor cells during embryonic development, as well as in mature tenocytes (Schweitzer et al., 2001). Recently, the important role of Scx in tendon healing has been shown through the implantation of scleraxisprogrammed tendon progenitors (hMSC-Scx), which enhanced the repair of a full-size rat Achilles tendon lesion (Hsieh et al., 2016). Although some key players and pathways of tendon development are known, still many aspects remain unclear and need to be further investigated.

On the other hand, the growth factor profile during tendon healing differs from the one of tendon development (Glass et al., 2014). Transforming growth factor beta 1 (TGF $\beta 1$ ) is present instead of TGF $32 / 3$, which in turn can activate IGF-1 secretion and, thus, have an impact on the functional recovery of the tendon (Chang et al., 2000a; Klein et al., 2002). PDGF and bone morphogenetic protein 12 (BMP12) are moderately expressed overtime in the midsubstance of the tendon (Wuergler-Hauri et al., 2007). Secreted by the platelets, FGF is also released at the wound site. The signalling pathways involved in development, TGF $\beta$-Smad2/3 and FGF-ERK/ MAPK, are also activated during the healing process (Nourissat et al., 2015); however, it needs to be further elucidated as to how they interact or integrate during these two processes. Increase in mRNA levels of genes encoding for collagen, tenomodulin, tenascin-C and proteoglycans are observed during tendon healing, as well as upregulated expression of Scx and Mohawk right after injury (Juneja et al., 2013; Scott et al., 2011). The timing of all these cellular events is poorly understood. During the inflammatory phase and beginning of proliferative phase of the healing process, different isomers of PDGF are released from the platelets at the wound site (Andrae et al., 2008).

PDGF-BB is a homodimer and one of the four isoforms (A, B, C and D) of the PDGF growth family. There are three cell-surface receptors through which PDGF signalling cascade takes place (PDGFR $\alpha \alpha$, PDGFR $\alpha \beta$ and PDGFR $\beta \beta$ ) (Andrae et al., 2008) (Fig. $3 \mathrm{~A})$. Once bound to its receptor, PDGF-BB initiates a signalling cascade and different cellular processes are affected through different signalling pathways (Fig. 3B). Some of the induced signalling pathways include Ras-MAPK, phosphoinositide 3-kinase (PI3K), phospholipase C gamma (PLC $\gamma$ ) and Janus kinase (JAK), which are involved in several cellular and developmental processes (Fig. 3B). For a comprehensive overview on the signalling pathways through which PDGF-BB elicits downstream cascades, refer to previous reviews on the topic (Andrae et al., 2008; Heldin and Westermark, 1999; Tallquist and Kazlauskas, 2004). PDGFR can also interact with integrins, through the $\mathrm{Na}^{+} / \mathrm{H}^{+}$exchanger regulatory factors (NHERFs) that link it to focal adhesion kinase and cytoskeleton (James et al., 2004; Veevers-Lowe et al., 2011). In turn, PDGFRs can be also affected by the ECM components (DeMali et al., 1999; Veevers-Lowe et al., 2011).

The tissue repair mechanisms induced upon PDGF-BB delivery are carried through its generic chemotactic, mitogenic and angiogenic properties, as well as its synergistic actions with other growth factors (Deuel et al., 1991; Lynch et al., 1987; Pierce et al., 1991). PDGF has chemotactic and mitogenic effects on neutrophils, macrophages and phagocytes, responsible for breakdown and cleaning of tissue debris, as well as on tenocytes that enter the wound site to regenerate the damaged tissue. We believe that its ability to stimulate tenocyte and tenoblast proliferation, collagen production, collagen crosslinks and some new vessel formation, can aid the tendon healing process in the initial stages and lead to a better tissue organisation and subsequently improved biomechanical properties. The proliferative effect on tenocytes and tenoblasts supports the intrinsic healing mechanism, by attracting these cell populations from the endotenon, which in turn can synthesise and remodel the ECM. On the other hand, there is an evidence that the effect of PDGF-BB on elastin synthesis is inhibitory, where the MAPK/ERK signalling pathway acts in opposition to canonical TGF $\beta 1$ signalling (Sproul and Argraves, 2013). However, its mechanism and role in tendon healing are yet unknown. Since tendons are hypovascular, in the long run, this can be a drawback for the healing process, where some vascularisation can provide extrinsic factors for a better healing (Barrientos et al., 


\section{A}

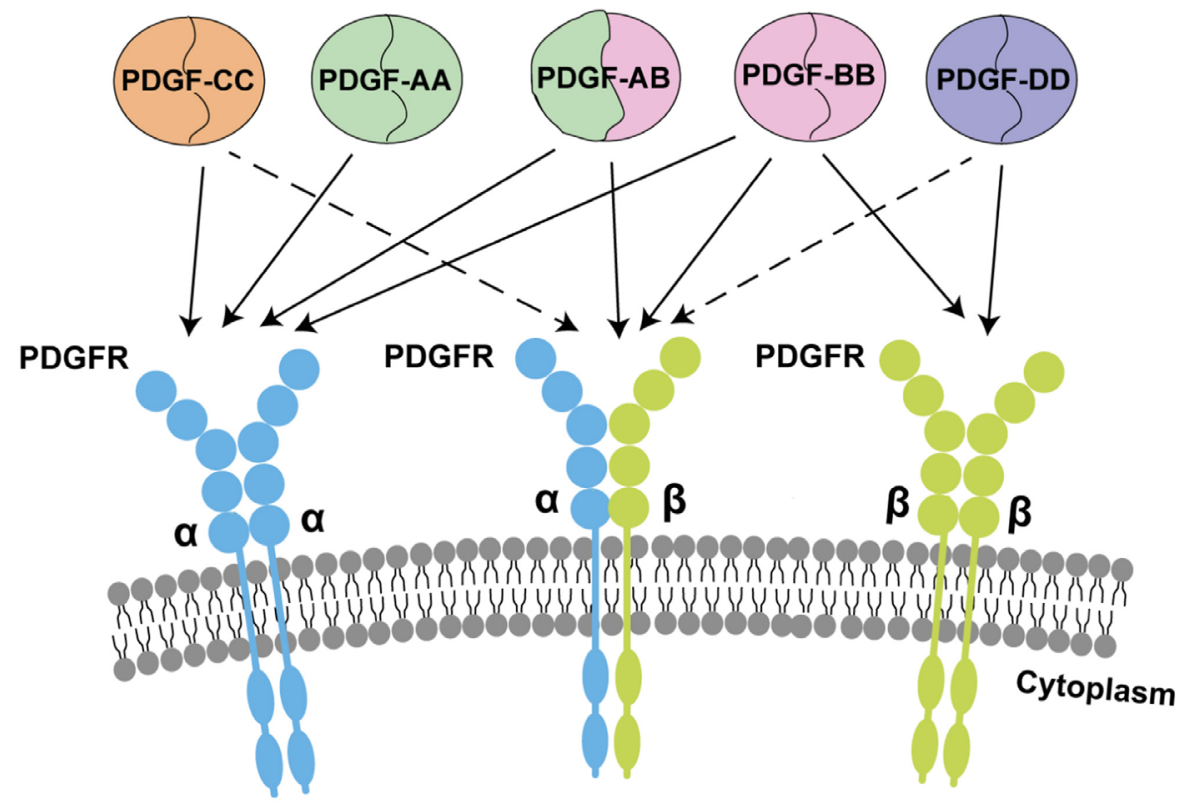

B
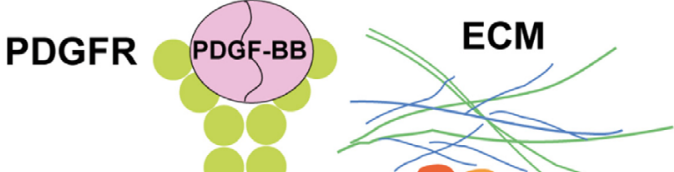

$\boldsymbol{\beta} \quad \boldsymbol{\beta} \quad \alpha_{\beta}$ Integrins

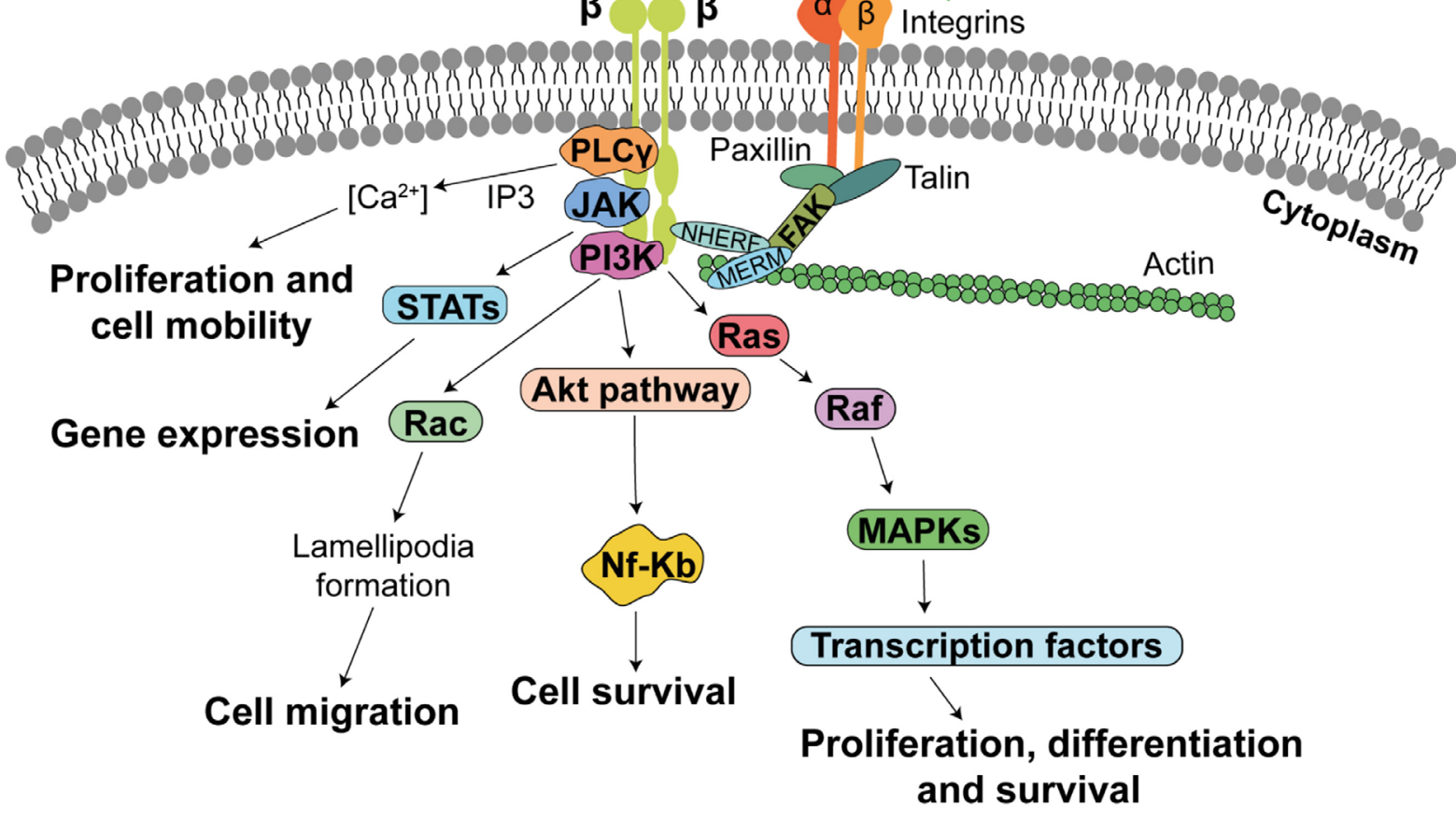

Fig. 3. PDGF binding and signalling pathways. (A) PDGF-PDGFR interactions, where each unit of the PDGF dimer interacts with one receptor subunit. The interactions shown have been determined in vitro; weak interactions or conflicting reports are represented with dashed lines. (B) Signalling pathways after PDGF-BB binding and interactions with the cytoskeleton and integrins. Simplified representation of the main players and actions where many other elements and processes, especially feedback mechanisms, have been omitted (based on Andrae et al., 2008). 




$\boldsymbol{t}$ (time)
Fig. 4. Illustration of different molecules release profiles from polymeric delivery devices. Burst release is not desired, since almost the entire molecule of interest is released at once and very little or nothing is released in the subsequent time. Sustained release, which offers a more controllable rate of release, little by little, without having a big decrease in the rate of release is desired for most delivery devices and in the best case they approach firstorder release kinetics. Zero-order kinetics allows for a constant rate of release of the molecule, independent on molecule concentration.
2014; Fenwick et al., 2002). In this regard, application of PDGF-BB can prove beneficial, rather than VEGF, which has been shown to have deleterious effect on tendon healing, resulting in abundant hypoxiainducible factor 1 (HIF-1)/VEGF-induced and matrix metallopeptidase 3 (MMP-3)-supported angiogenesis with inferior biomechanical properties of the tendons (Sahin et al., 2012). The clinical efficacy of PDGF-BB (rhPDGF-BB) use in wound healing has been shown in several phase III studies, where its application is well tolerated and safe (Smiell et al., 1999).

\section{Part A: Effects of PDGF-BB delivery in vitro}

\section{Need for controlled and sustained release of PDGF- BB}

Considering the healing process of acutely injured tendons, the correct timing of PDGF-BB administration is critical in determining the effectiveness of the growth factor therapy. Moreover, how PDGF-BB is delivered plays a role in whether the growth factor will be cleared right after administration or not. While PDGF-BB is ineffective when it is applied directly after injury [by injection (bolus)] or burst-released from a delivery device - which causes fast clearance of the growth actor at the wound site (Robinson and Talmadge, 2002) - a sustained release - allowing PDGF-BB presence at later time points, especially $7 \mathrm{~d}$ post-injury (Gulotta and Rodeo, 2009) - can lead to beneficial effects in terms of healing. Release refers to the process in which the molecule, i.e. growth factor of interest, migrates from the initial place within the polymeric system into the polymer's outer surface and then to the release medium (example: wound site) (Langer, 1990). The release is a process that is affected by different factors, including the structural characteristics of the delivery system, the method used to incorporate the molecule into the delivery system, the release environment etc.. Optimally, a delivery device should have a release profile approaching zero-order kinetics, meaning that the release of the molecule of interest takes place at a constant rate, independent of the molecule concentration involved in the process (Fig. 4). A burst release is characterised by an initial large release of the molecule from the system (within hours or days) without further changes within time. However, a sustained release offers a release of the molecule from the system in a controlled manner, little by little, at every time point, without having a large decrease in the rate of release. Most of the sustained release delivery devices result, at best, in first-order release kinetics. This can fit well in the case of PDGF-BB delivery device, where its presence would be desired $7 \mathrm{~d}$ post-injury, with a subsequent decrease and disappearance to avoid hypercellularity at the repair site. So far, several approaches have been tested for its delivery, which include heparin-based PDGF-BB immobilisation within different delivery devices or incorporation within polymeric scaffolds using different electrospinning techniques.

\section{Heparin-based strategies for sustained PDGF-BB delivery}

Heparin is a highly sulphated glycosaminoglycan, possessing moderate or strong binding affinity for several growth factors, including PDGF, FGF, TGF $\beta$ and VEGF (Guan et al., 2004; Lyon et al., 1997; Mangrulkar et al., 1995). Investigated primarily with a focus to reduce thrombogenicity of materials in contact with blood, its use also spread to the development of drug delivery constructs. Through electrostatic interactions, the negatively-charged heparin molecules bind positively-charged growth factors, such as PDGF-BB, preventing quick diffusion 
and retaining their bioactivity with protection from heat, $\mathrm{pH}$ and enzymatic degradation (Guan et al., 2004). Heparin-based approaches for loading growth factors into constructs for tissue engineering applications have been used for different delivery systems including fibrin-based matrix (Thomopoulos et al., 2007) and electrospun polymeric fibres (Lee et al., 2012b).

\section{Heparin-conjugated systems}

These approaches utilise covalent immobilisation of heparin onto biomaterials by covalently binding it to proteins, such as collagen or albumin, using 1-ethyl3-(3-dimethylaminopropyl) carbodiimide (EDC)/Nhydroxysuccinimide (NHS) chemistry (Hennink et al., 1983; Wissink et al., 2000; Wissink et al., 2001). A demineralised bone matrix has been successfully crosslinked with heparin and loaded with PDGF-BB allowing for its sustained delivery and bioactivity retention (Sun et al., 2009). Heparin conjugation with electrospun polymeric fibres with subsequent PDGF-BB loading (Fig. 5A) has been done in only a few studies using poly ( $\varepsilon$-caprolactone) (PCL)/gelatin fibres (Lee et al., 2012b), poly(L-lactide) fibres (plasma assisted heparin conjugation) (Cheng et al., 2014) and PCL/gelatin electrospun fibres (Lee et al., 2012a; Lee et al., 2012b), where cellular bioactivity and cell infiltration were studied.

\section{Fibrin-based delivery devices}

The fibrin-based delivery system with heparinimmobilised PDGF-BB is the only one that has been explored for tendon regeneration application (Sakiyama-Elbert and Hubbell, 2000a; SakiyamaElbert and Hubbell, 2000b; Thomopoulos et al.,
2007). This delivery system is based on a bi-domain peptide that includes a factor XIIIa substrate, derived from $\alpha_{2}$-plasmin inhibitor, at the $\mathrm{N}$-terminus and a heparin-binding domain at the C-terminus. During coagulation, the bi-domain peptide is covalently crosslinked to the fibrin matrix by factor XIIIa. Heparin is immobilised electrostatically at the C-terminus and PDGF-BB is subsequently bound to heparin (Fig. 5B). In this system, compared to other heparin-based delivery systems, where heparin is covalently bound to the delivery construct, a noncovalent immobilisation is performed using primarily electrostatic interactions with the heparin-binding peptide. The release of PDGF-BB from the matrix can occur by dissociation from the matrix-bound heparin and subsequent diffusion, proteolytic degradation of the fibrin matrix and/or enzymatic degradation of heparin (Gelberman et al., 2007).

Electrospinning - another approach for producing bioactive scaffolds delivering PDGF-BB

Electrospinning allows for production of scaffolds from different natural and synthetic polymers, fibrous and porous in structure, resembling the extracellular matrix (Rim et al., 2013). Further modifications of the chemical, biological and mechanical properties of the scaffolds allow for advancements in applications. Methods for incorporation of bioactive molecules, like growth factors, within electrospun scaffolds, include physical adsorption (Kovacevic et al., 2015) of biomolecules onto scaffolds, blend electrospinning, emulsion electrospinning and coaxial electrospinning (Fig. 6). While physical adsorption and blend electrospinning often result in burst release and can also cause growth factor denaturation, emulsion
A PCL /gelatin fibre based binding
heparin and PDGF - BB

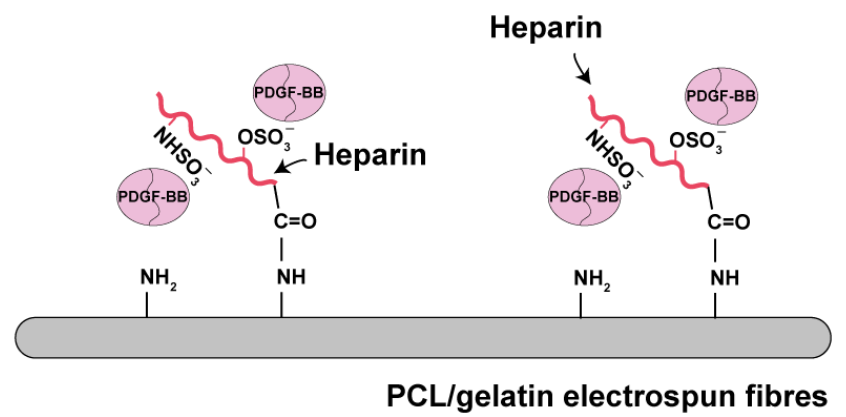

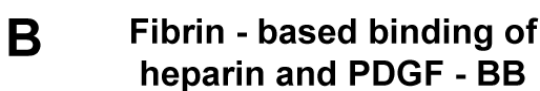



Fig. 5. Scheme of heparin-based delivery strategies for PDGF from different delivery matrices. (A) Scheme of heparin-conjugated electrospun PCL/gelatin fibres as a delivery device. The binding of PDGF-BB takes place in two steps. First, heparin is bound to the PCL/gelatin fibres through the formation of amide bonds, using EDC/NHS chemistry for activation of the carboxyl groups of heparin. Next, incubation with aqueous PDGF-BB allowed its immobilisation through electrostatic interactions with the heparin molecule. (B) Scheme of fibrin-based delivery system. During coagulation, a bi-domain peptide is covalently crosslinked to the fibrin matrix by factor XIIIa. Heparin is immobilised electrostatically at the C-terminus and PDGF-BB bound to heparin through electrostatic interactions is also immobilised within the carrier (Lee et al., 2012a; Lee et al., 2012b; Thomopoulos et al., 2007). 
and coaxial electrospinning are more promising approaches for a sustained PDGF-BB delivery.

In vitro sustained PDGF-BB delivery leads to similar biological responses to media supplemented PDGF-BB

Several characterisation studies throughout the years have been performed to determine the effects of PDGF$\mathrm{BB}$ on tenocytes or tenoblasts in in vitro conditions, while its effects on tendon progenitor stem cells have not yet been tested. One of the main responses upon addition of PDGF-BB in a dose-dependent manner, either in serum free or complete culture medium, is the increase in proliferation of tenocytes (Table 1) (Banes et al., 1995; Caliari and Harley, 2011; Costa et al., 2006; Evrova et al., 2016; Thomopoulos et al., 2005; Wong et al., 2003). Typically, the increase in cell proliferation has been assessed by metabolic activity assays or DNA synthesis quantification assays, while not exploring which pathway exactly led to the observed response. Maintaining tenocyte phenotype, while accelerating cell proliferation in the initial reparative phase, would be useful for aiding the initial tendon healing. Increase in collagen synthesis upon PDGF-BB addition has also been observed in a concentration-dependent manner, where the effect plateaued at a concentration of $20 \mathrm{ng} / \mathrm{mL}$, which could be due to saturation of available cell receptors for certain growth factor (Costa et al., 2006; Yoshikawa and Abrahamsson, 2001). Typically, 5-100 ng/mL PDGF-BB have been used as supplementation in in vitro experiments (Table 1 ), offering only an idea for the dosage that might be used in delivery devices or experiments in vivo.

Using the heparin-conjugation system, a demineralised bone matrix, as well as electrospun polymeric fibres successfully crosslinked with heparin and subsequently loaded with PDGF-BB,
A

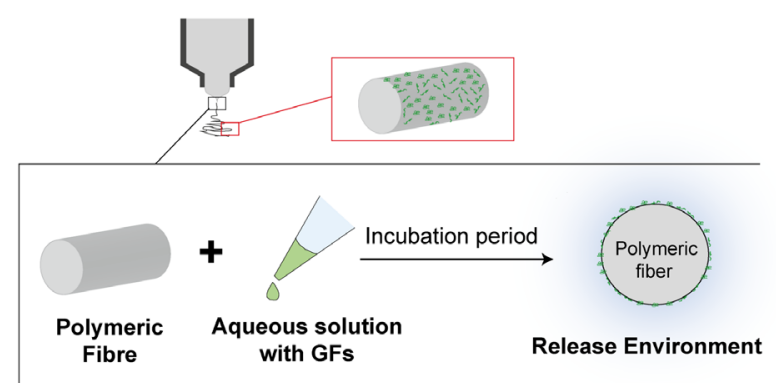

B



C Emulsion Electrospinning

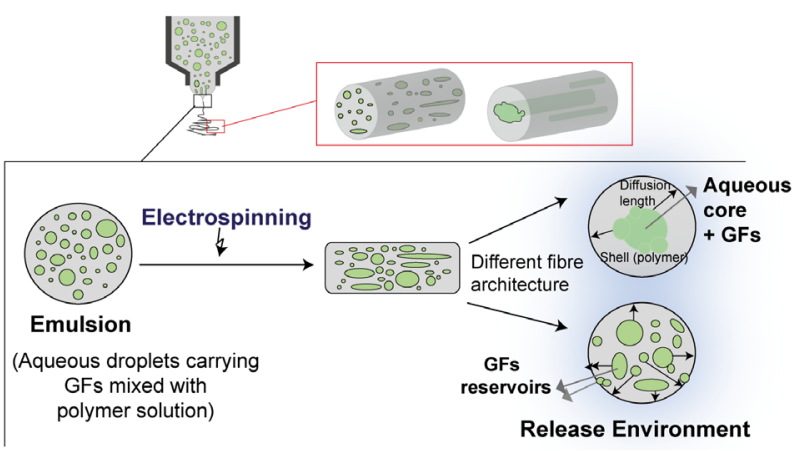

D Coaxial Electrospinning

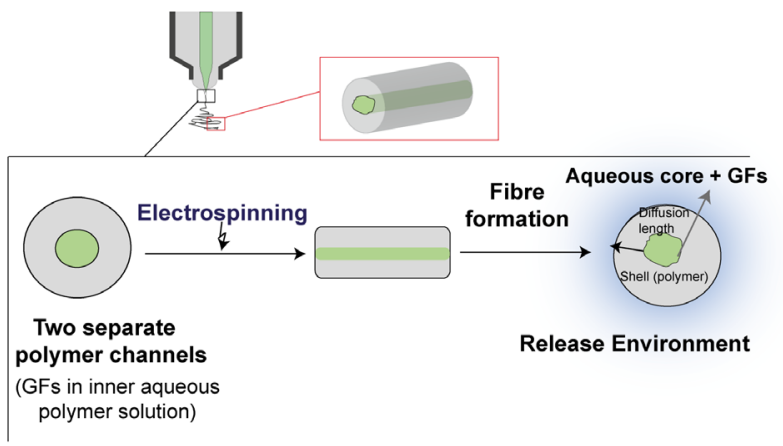

Fig. 6. Schematic overview of different electrospinning methods for growth factor (GF) incorporation within polymeric scaffolds. (A) Single electrospinning allows for standard polymeric fibres to be obtained from a polymer solution where afterwards growth factors (GFs) can be physically adsorbed onto. (B) Blend electrospinning allows GF incorporation into the polymeric fibres by simply dispersing the GF directly into the polymer solution and electrospinning this mix. However, this is not a preferred method, since biomolecules can be damaged/denatured by the presence of organic solvents in the polymer solution. Usually delivery devices obtained with this method exhibit a burst release of biomolecules from the fibres. (C) Emulsion electrospinning allows for GF incorporation initially in an aqueous solution, which forms the aqueous phase of the water-in-oil (w/o) emulsion, where the polymer solution is the oil phase. This method allows for better protection of the GF in the presence of organic solvents and results in devices with a burst or a sustained release profile. (D) Coaxial electrospinning allows core-shell formation within the polymeric fibres, where the aqueous phase, carrying the GF of interest, constitutes the core within the fibres. Being in the aqueous phase, the GF are protected within the polymer shell and usually their release is in a sustained manner, rather than a burst release, governed by GF diffusion from the core and pore formation within the polymer shell. 
Table 1. Summary of in vitro tested conditions and cellular responses upon PDGF-BB administration.

\begin{tabular}{|c|c|c|c|c|}
\hline In vitro model & $\begin{array}{c}\text { PDGF } \\
\text { concentration }\end{array}$ & Administration & Time point & Cellular response \\
\hline $\begin{array}{c}\text { Avian flexor tendon } \\
\text { epitenon cells; internal } \\
\text { fibroblasts (tenocytes) } \\
\text { (P2-P4) (Banes et al., } \\
1995)\end{array}$ & $10,50,100 \mathrm{pM}$ & $\begin{array}{l}\text { Supplemented in } \\
\text { serum free culture } \\
\text { medium-1d }\end{array}$ & $1 \mathrm{~d}$ & $\begin{array}{c}\text { DNA synthesis } \uparrow \text { in a } \\
\text { dose-dependent manner } \\
\text { in both cell populations. } \\
\text { Mechanical stimulation } \\
\text { had synergistic role on } \\
\text { DNA synthesis } \\
\end{array}$ \\
\hline $\begin{array}{l}\text { Canine intrasynovial } \\
\text { flexor tendon } \\
\text { fibroblasts (P2+) } \\
\text { (Thomopoulos et al., } \\
\text { 2005) }\end{array}$ & $\begin{array}{l}10 \mathrm{ng} / \mathrm{mL} \\
\text { or } 2-100 \mathrm{ng} / \\
\mathrm{mL} \text { in } \\
\text { combination } \\
\text { with bFGF }\end{array}$ & $\begin{array}{l}\text { Supplemented in } \\
\text { serum-free culture } \\
\text { medium }\end{array}$ & $1 \mathrm{~d}$ & \begin{tabular}{|c|} 
Cell proliferation $\uparrow$ \\
Total collagen synthesis $\uparrow$ \\
Synergistic effect together \\
with bFGF (within 5-40 ng/ \\
mL for DNA synthesis and \\
5-20 ng/mL for collagen \\
synthesis)
\end{tabular} \\
\hline $\begin{array}{c}\text { Rabbit flexor tendon } \\
\text { (synovial sheath, } \\
\text { epitenon and } \\
\text { endotenon) tenocytes } \\
\text { (P4 or less) (Costa et al., } \\
\text { 2006) } \\
\end{array}$ & $\begin{array}{c}1,10 \text { or } 50 \mathrm{ng} / \\
\mathrm{mL}\end{array}$ & $\begin{array}{l}\text { Supplemented in } \\
\text { serum-free culture } \\
\text { medium }\end{array}$ & $3 d$ & $\begin{array}{l}\text { Cell proliferation } \uparrow \text { in a } \\
\text { dose-dependent manner }\end{array}$ \\
\hline $\begin{array}{l}\text { Equine digital flexor } \\
\text { tenocytes (P2-3) } \\
\text { (Caliari and Harley, } \\
\text { 2011) }\end{array}$ & $\begin{array}{c}10,50 \text { or } \\
100 \mathrm{ng} / \mathrm{mL}\end{array}$ & $\begin{array}{l}\text { Supplemented in se- } \\
\text { rum-free culture me- } \\
\text { dium with tenocytes } \\
\text { seeded on collagen- } \\
\text { GAG scaffolds } \\
\end{array}$ & $1 \mathrm{~d}, 4 \mathrm{~d}, 7 \mathrm{~d}$ & $\begin{array}{c}\text { Cell proliferation } \uparrow \\
\text { Cell metabolic activity } \uparrow\end{array}$ \\
\hline $\begin{array}{c}\text { Equine digital flexor } \\
\text { tenocytes (P4) (Caliari } \\
\text { et al., 2014) }\end{array}$ & 100 ng/mL & $\begin{array}{l}\text { Supplemented in } \\
\text { serum }{ }^{+} \text {culture } \\
\text { medium }\end{array}$ & $1 \mathrm{~d}$ & $\begin{array}{c}\text { Tenocyte migration } \\
\text { through collagen-GAG } \\
\text { scaffold } \uparrow\end{array}$ \\
\hline $\begin{array}{l}\text { Rabbit Achilles tendon } \\
\text { tenocytes (P1-P4) } \\
\text { (Evrova et al., 2016) }\end{array}$ & $\begin{array}{l}1-50 \mathrm{ng} / \mathrm{mL} \\
\text { or delivered } \\
\text { by emulsion } \\
\text { electrospun } \\
\text { scaffolds }\end{array}$ & $\begin{array}{l}\text { Supplemented in } \\
\text { serum }{ }^{+} \text {and serum- } \\
\text { free medium; PDGF- } \\
\text { BB delivered from } \\
\text { bioactive scaffolds }\end{array}$ & $\begin{array}{l}1 \mathrm{~d}, 3 \mathrm{~d} \\
7 \mathrm{~d}, 14 \mathrm{~d} \\
1 \mathrm{~d}\end{array}$ & \begin{tabular}{|c|} 
Cell proliferation $\uparrow$ (serum \\
free conditions); this effect \\
was not significant in \\
serum conditions. \\
Cell proliferation of \\
tenocytes on bioactive \\
scaffolds $\uparrow$ \\
\end{tabular} \\
\hline $\begin{array}{c}\text { Human patellar } \\
\text { tendon tenocytes } \\
\text { (P2-P4) (Wong et al., } \\
\text { 2003) }\end{array}$ & $10 \mathrm{ng} / \mathrm{mL}$ & $\begin{array}{l}\text { Supplemented } \\
\text { in serum culture } \\
\text { medium }\end{array}$ & $2 \mathrm{~d}$ & \begin{tabular}{|c|} 
PDGF-BB reversed the \\
effects of dexamethasone \\
which led to cell viability/ \\
proliferation $\downarrow$ and collagen \\
synthesis $\downarrow$
\end{tabular} \\
\hline $\begin{array}{l}\text { Human hamstring } \\
\text { tenocytes (P3) (Qiu et } \\
\text { al., 2014) }\end{array}$ & $\begin{array}{c}5,10,50 \mathrm{ng} / \\
\mathrm{mL}\end{array}$ & $\begin{array}{l}\text { Supplemented in } \\
\text { serum-free culture } \\
\text { medium }\end{array}$ & $\begin{array}{l}1 \mathrm{~d}, 7 \mathrm{~d} \\
14 \mathrm{~d}\end{array}$ & $\begin{array}{c}\text { Cell proliferation } \uparrow \\
\text { Slight total collagen } \uparrow \\
\text { Tenomodulin, scleraxis, } \\
\text { decorin expression } \downarrow \\
\end{array}$ \\
\hline $\begin{array}{l}\text { Rabbit intrasynovial } \\
\text { flexor tendon and } \\
\text { extrasynovial peroneal } \\
\text { tendon explants } \\
\text { (Yoshikawa and } \\
\text { Abrahamsson, 2001) }\end{array}$ & $0.1-100 \mathrm{ng} / \mathrm{mL}$ & $\begin{array}{l}\text { Supplemented in } \\
\text { serum-free culture } \\
\text { medium }\end{array}$ & $4 \mathrm{~d}$ & $\begin{array}{c}\text { Proteoglycan synthesis, } \\
\text { collagen synthesis and cell } \\
\text { proliferation } \uparrow\end{array}$ \\
\hline $\begin{array}{c}\text { Equine superficial } \\
\text { digital flexor tendon } \\
\text { explants (Haupt et al., } \\
\text { 2006) }\end{array}$ & $\begin{array}{l}1,10,50 \text { or } \\
100 \mathrm{ng} / \mathrm{mL}\end{array}$ & $\begin{array}{l}\text { Supplemented in } \\
\text { culture medium with } \\
\text { reduced serum }(2 \%)\end{array}$ & $6 \mathrm{~d}$ & \begin{tabular}{|c|} 
Type I collagen gene \\
expression $\uparrow$ \\
Cell proliferation, GAG \\
and total collagen content \\
- n.a.
\end{tabular} \\
\hline
\end{tabular}


have been shown to successfully retain PDGF$\mathrm{BB}$ bioactivity and allow for sustained delivery, compared to physically adsorbed PDGF-BB. The same delivery devices, with physically adsorbed PDGF-BB, exhibited a burst release of the growth factor within the first 3-4 d (Lee et al., 2012a; Sun et al., 2009).

Studies on tendon explants have shown results similar to cell cultures. Stimulated cell proliferation and collagen synthesis, upon PDGFBB supplementation in the culture medium, were observed in intermediate and proximal intrasynovial flexor and extrasynovial peroneal tendon segments (Yoshikawa and Abrahamsson, 2001). On the other hand, Haupt et al. (2006), in a study on equine tendon explant, reported different results regarding the effect of PDGF-BB. No changes in morphology of the tendons, nor proliferative changes were detected upon addition of different concentrations of PDGF$\mathrm{BB}$. High concentrations led to increase in collagen type I gene expression and decrease in collagen type III gene expression, with no changes in the glycosaminoglycan content.

PDGF-BB was also shown to play a role in the regulation of different integrin receptors, namely alpha(v)beta3 and alpha5beta1 receptors. These specific integrins can be important in intrasynovial flexor tendon healing, since alpha5beta1 is involved in fibronectin deposition, as part of the provisional formed matrix. ECM remodelling might play a role in mechanotransduction (Regent et al., 2011), while alpha(v)beta3 is involved in angiogenesis/ revascularisation (Brooks et al., 1994; HodivalaDilke, 2008). Semi-quantitative reverse transcription PCR showed that PDGF-BB increased expression of alpha(v) mRNA 3-fold, whereas alpha5 expression was increased 2-fold in intrasynovial flexor tendon cells (Harwood et al., 1999).However, not much is known about effect of PDGF-BB on tendon specific markers, such as Scx or tenomodulin. Qiu et al. (2014), exploring different growth factor combinations for serum-free tenocyte expansion, observed a decrease in Scx, tenomodulin and decorin gene expression after 14 d, upon PDGF-BB supplementation. Tenocytes, cultured for $14 \mathrm{~d}$ in $50 \mathrm{ng} / \mathrm{mL}$ of PDGF, showed a similar expansion trend compared to tenocytes cultured in $10 \%$ FBS (control group) and a slight increase in total collagen content and gene expression of type I collagen. Younesi et al. (2016) showed a decrease in Scx, tenomodulin and type I collagen gene expression in tenocytes cultured on collagen threads with immobilised PDGF-BB, in comparison to collagen threads only, but an increase in gene expression when compared to collagen gels.

Similar to media-supplemented PDGF-BB, different studies have addressed the bioactivity of PDGF-BB after being delivered by the system. These studies have assessed the effect of PDGF-BB on cell proliferation, i.e. increase in DNA content (Table 2).

So far, the most widely characterised delivery device for in vitro conditions has been a fibrin- based delivery system that allows immobilisation of heparin-binding growth factors, such as PDGF$\mathrm{BB}$, thus protecting them from degradation prior to release at the tendon injury site (Sakiyama-Elbert and Hubbell, 2000a; Sakiyama-Elbert et al., 2008) (Table 2). This system, allowing for a sustained PDGFBB delivery over a period of $10 \mathrm{~d}$, has significant advantages compared to the bolus application of growth factors (growth factors are cleared within 48 h) (Robinson and Talmadge, 2002) or traditional synthetic polymeric delivery systems that can create acidic environment during degradation (Zisch et al., 2003). Tested in vitro on canine tenocytes, fibrin matrices with PDGF-BB led to a significant increase in total DNA, compared to martices without PDGF-BB or matrices with PDGF-BB but without the delivery system. After $6 \mathrm{~d}$ in culture, collagen synthesis was enhanced to a greater extent by controlled delivery of PDGF-BB, rather than by PDGF-BB in fibrin matrices without delivery system, suggesting a need for its sustained delivery over time (Sakiyama-Elbert et al., 2008). In a subsequent study, sustained delivery of PDGF-BB from the fibrin system resulted in downregulation of collagen (Col I and Col III) and lubrican gene expression at day 5 . This suggests that downregulation of collagen genes by PDGF-BB may not necessarily translate into decreased production of collagen or that specific post-transcriptional events can play a role (Thomopoulos et al., 2010a). Additionally, it has been suggested that PDGFBB does not directly affect collagen synthesis, but rather that it is a potent chemoattractant for wound macrophages and fibroblasts, which may stimulate endogenous increase in TGF $\beta$ and, in turn, stimulate new collagen synthesis and enhancement in wound healing (Pierce et al., 1989).

Due to the fact that the solely fibrin-based delivery system might not provide a surgically manageable construct for tendon repair, Manning et al. (2013) improved its structural integrity by layering it with an electrospun poly(lactic acid-co-glycolic acid) (PLGA) backbone and incorporating adipose-derived mesenchymal stem cells into the fibrin-based delivery system. The bioactivity of the delivered PDGF-BB was not directly assessed but, over a period of $14 \mathrm{~d}$, the cell viability within the scaffolds was not affected.

Another delivery device tested for tendon healing application was an emulsion electrospun DegraPol ${ }^{\mathbb{R}}$ scaffold with incorporated PDGF-BB. When assessed in vitro, tenocytes showed increased proliferation as a result of released PDGF-BB in serum-free conditions or when directly seeded on bioactive scaffolds in serum conditions, thus showing PDGF-BB retained its bioactivity during the electrospinning process (Evrova et al., 2016).

PDGF-BB delivery has been tested for other applications as well, where different delivery strategies were used (summarised in Table 2). In most studies, testing the bioactivity of incorporated and released PDGF-BB was done by looking at increase in cell proliferation, as the most pronounced biological 


\begin{tabular}{|c|c|c|c|c|c|c|c|c|c|c|}
\hline 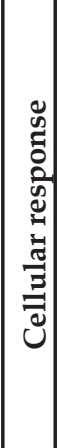 & 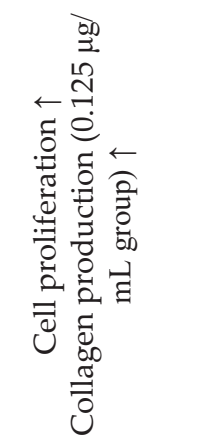 & 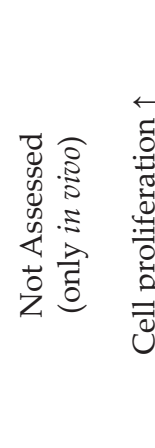 &  & 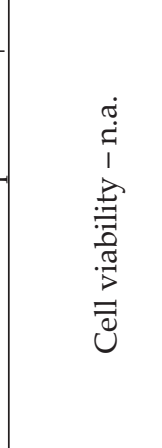 & 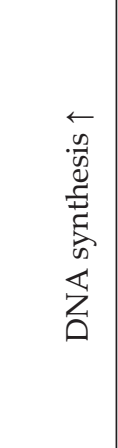 & 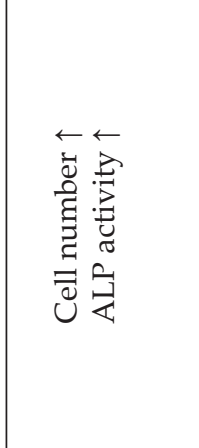 & 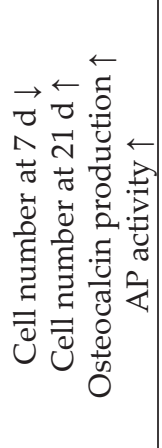 &  & 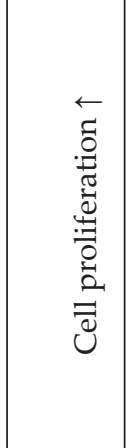 & 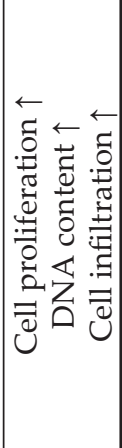 \\
\hline 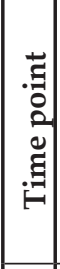 & $\tilde{0}$ & 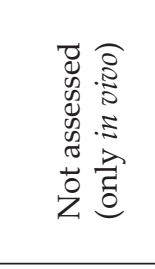 & $\begin{array}{l}\overrightarrow{0} \\
\stackrel{0}{1} \\
\vec{i} \\
\text { in }\end{array}$ &  & $\stackrel{\tau}{\longrightarrow}$ & $\begin{array}{l}\overrightarrow{0} \\
\overrightarrow{7} \\
\vec{\sigma} \\
\overrightarrow{+}\end{array}$ & $\begin{array}{l}\vec{D} \\
\vec{N} \\
\vec{D} \\
\end{array}$ & 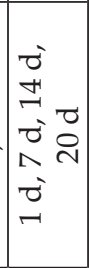 & $\underset{+}{T}$ & 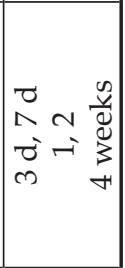 \\
\hline  & 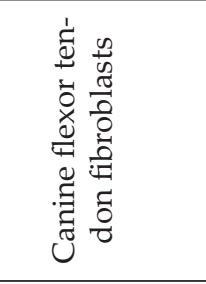 & 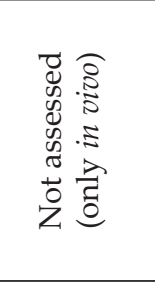 & 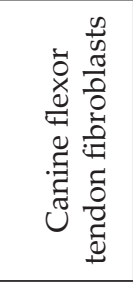 & 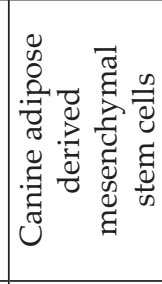 & 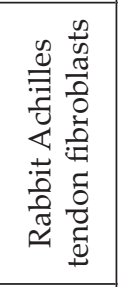 & 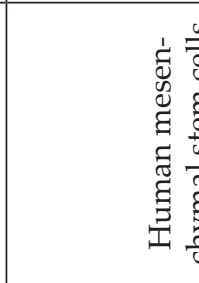 & & $\begin{array}{l}\stackrel{\infty}{\infty} \\
\stackrel{D}{\Xi} \\
\end{array}$ & 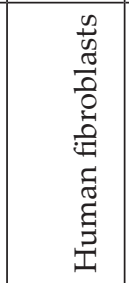 & 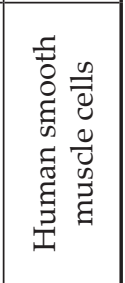 \\
\hline  &  &  &  & 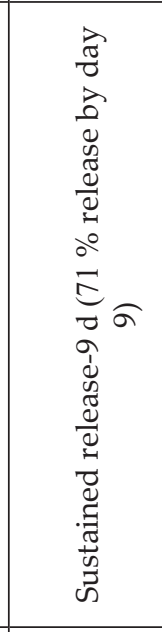 & 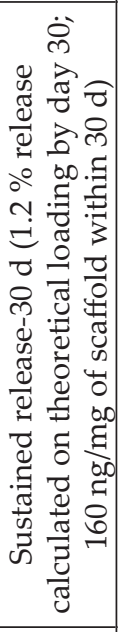 &  & 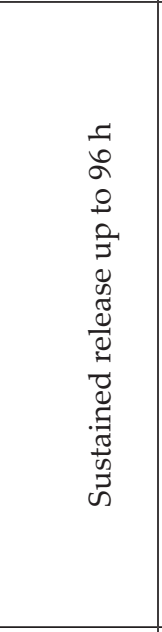 &  & 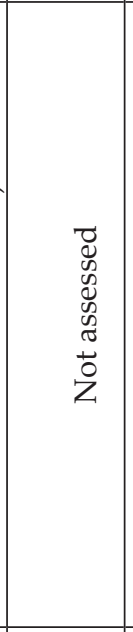 & 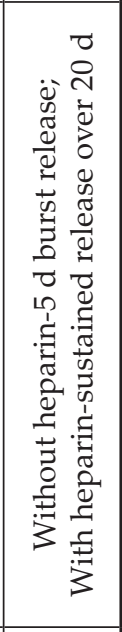 \\
\hline 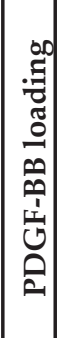 & 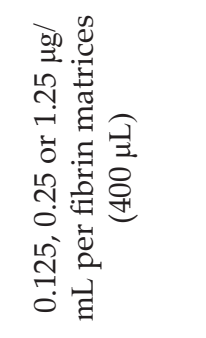 & 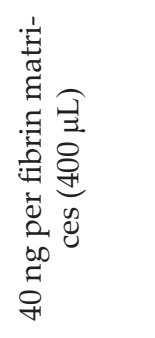 &  & 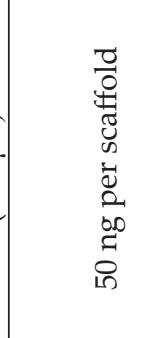 & 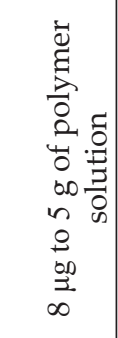 & 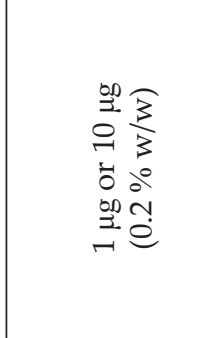 & $\begin{array}{rl} & \frac{3}{3} \\
3 & 0 \\
0 & 0 \\
0 & 0 \\
0 & 0\end{array}$ & 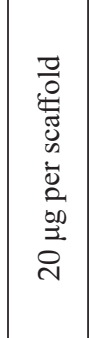 & 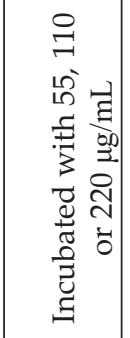 & 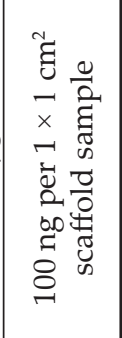 \\
\hline 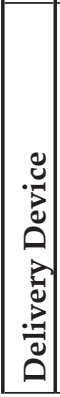 & 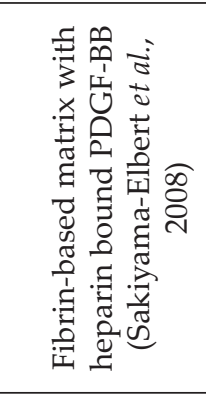 & 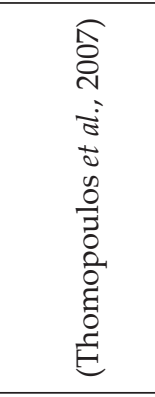 & 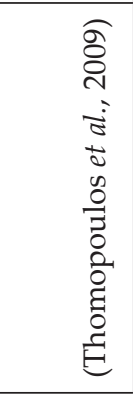 & 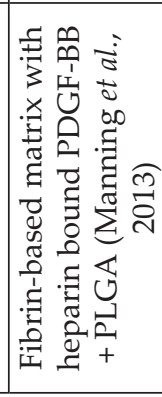 &  &  & 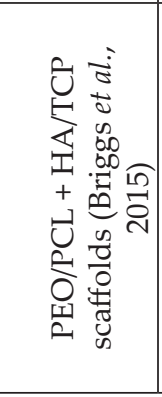 &  & 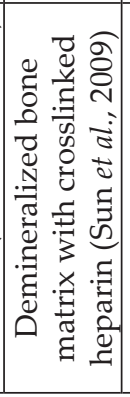 & 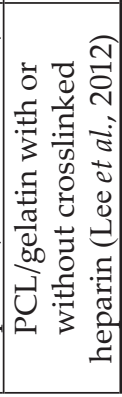 \\
\hline
\end{tabular}


outcome after PDGF-BB supplementation (Table 2). Significant increase in cell proliferation upon PDGF-BB delivery, using different systems, was usually observed after 4 or $7 \mathrm{~d}$, similar to PDGF-BB supplemented directly in the culture medium (Table 1). When DNA synthesis was studied, a short time point of $24 \mathrm{~h}$ was used for the delivery devices or media supplementation and a significant increase in DNA synthesis after PDGF-BB stimulation was observed in both cases (Table 1,2). However, besides the well-established proliferative effects, more systematic studies on the effect of PDGF-BB on some of the tendon specific markers in tenocytes and tendon stem cells are needed in order to obtain more conclusive insight about its possible impact in tendon healing.

The loaded amounts of PDGF into the delivery devices explored (Table 2) are generally larger than the amounts supplemented directly in culture medium (Table 1). However, usually $100 \%$ loading efficiency within the device is not achieved and beside the sustained delivery they offer, still in some systems, under in vitro conditions, large amounts of encapsulated PDGF-BB are not released. Taking this into account, the amount of released PDGF-BB over time could be smaller or comparable to the media supplemented one, which, on the other hand, can drastically differ once the delivery device is used in in vivo conditions.

PDGF-BB delivery device design: easy handling, surgery compatibility and sustained release kinetics are important for successful application in tendon repair

Most strategies explored for PDGF-BB delivery experienced a sustained release of PDGF-BB over a period of several days (Table 2). A sustained release of growth factor was achieved using heparin immobilisation on PCL/gelatine scaffolds, where physical adsorption of PDGF-BB on the scaffolds resulted in a burst release within the first 3-4 d (Lee et al., 2012b).

The release kinetics of PDGF-BB from the fibrinmatrix-based delivery system can be modulated by different molar ratios of PDGF-BB to heparin, different amounts of PDGF-BB loading and also different gel size (Sakiyama-Elbert et al., 2008). In in vitro conditions, decreasing the molar ratio of PDGF-BB to heparin, from $1: 10$ to $1: 10,000$, led to significantly more sustained delivery of PDGF-BB within 10 d (Sakiyama-Elbert et al., 2008; Thomopoulos et al., 2007). Three different doses of PDGF-BB loading were evaluated $(0.125,0.25$ and $1.25 \mu \mathrm{g} / \mathrm{mL})$, where increase in the amount loaded led to more sustained release. Varying the fibrin matrix size did not have a major effect on the release rate of PDGF-BB and its passive release should correlate between different matrix volumes (Sakiyama-Elbert et al., 2008). The release of PDGF-BB from the fibrinbased matrices was tested in the presence of cells and it was observed that its release is in a dose-dependent manner and similar to the in vitro passive release (Sakiyama-Elbert et al., 2008).

The explored electrospun scaffolds, produced with either emulsion or coaxial electrospinning, also allow for sustained PDGF-BB delivery (Table 2). PDGF$\mathrm{BB}$ has been incorporated within PCL and PCL/ poly(ethylene oxide) (PEO) electrospun scaffolds, intended for bone tissue engineering applications (Briggs and Arinzeh, 2013; Briggs et al., 2015). These types of scaffolds allow for sustained delivery of PDGF-BB over a period of $4 \mathrm{~d}$, but without complete release of the growth factor from the polymeric scaffolds, while a fraction of it is likely to be bound to the scaffold in a bioactive form (Briggs et al., 2015). Recently, DegraPol ${ }^{\circledR}$, an elastic polyester urethane, block copolymer, has been studied as a delivery device for PDGF-BB. It allowed for the successful incorporation and sustained release of PDGF-BB within a period of $30 \mathrm{~d}$. However, similar to the PCL and PCL/PEO scaffolds, a large amount of growth factor was still inside the scaffold or strongly bound to the surface and, therefore, not released (Evrova et al., 2016). PDGF-BB has been successfully incorporated in the core of PCL and PCL/polyethylene glycol (PEG) fibres (Liao et al., 2006). Incorporation of PEG in the PCL shell through blending, rendered the fibres permeable to protein by inducing swelling and pore formation. The release kinetics could be controlled by varying the nature and amount of PEG in the shell of the nanofibres. Absence of PEG in the shell layer resulted in negligible release of PDGF-BB since PDGF-BB itself cannot generate open pores throughout the shell layer. A very small amount is in the core of the fibres and the diffusion through the bulk PCL shell could be too slow to take place in the desired time frame (Jiang et al., 2014). In the different scaffolds tested, PDGF-BB exhibited sustained release profile over $35 \mathrm{~d}$ and it was shown to be bioactive (Liao et al., 2006). Li and co-workers have produced dextran (DEX)/poly(L-lactide-co-epsiloncaprolactone) (PLCL) coaxially electrospun fibres carrying PDGF-BB. In their studies, the electrospun scaffolds showed a burst release of PDGF-BB in the first $2 \mathrm{~d}$, followed by a steadier release up to $28 \mathrm{~d}$ ( $\mathrm{Li}$ et al., 2010).

So far, for tendon repair applications, coaxial electrospun scaffolds have not been utilised for delivery of PDGF, neither in vitro nor in vivo, while emulsion electrospun scaffolds have been explored in vitro. These techniques might offer an advantage over the heparin-based delivery systems. One disadvantage of the heparin-based delivery systems lie in the preparation step. The conjugation of heparin to the polymeric scaffold requires the immersion and incubation of the device with all the necessary solutions, including the heparin solution, and in the next step the incubation with PDGF solution. This process allows for complete conjugation of the scaffold with heparin and subsequently PDGF. However, once applied at the tendon injury site, PDGF delivery is desired preferably towards the 
tendon and not the surrounding tissue, where its diffusion can affect neighbouring cells and lead to undesired side effects, such as adhesion formation (Meier Buergisser et al., 2014; Meier Buergisser and Buschmann, 2015). Because of this, layered scaffolds could be considered as an alternative, which might allow for more spatial selection for PDGF delivery primarily towards the tendon tissue.

Using electrospinning techniques, a physical separation between the bioactive layer of the scaffold and the surrounding tissue of a tendon can be achieved, with a directed, localised delivery of PDGFBB. Recently, this approach was associated with the use of a double-layered DegraPol ${ }^{\circledR}$ tube that has a bioactive and non-bioactive layer, to be applied over ruptured and conventionally sutured tendon in order to promote tendon healing with PDGF-BB delivery (Evrova et al., 2016).

\section{PART B: Effects of PDGF-BB delivery in vivo}

\section{Impacts of PDGF-BB}

Although in vitro release studies are necessary for the characterisation of a delivery device, in vivo experiments and assessments are absolutely needed to discover its real effects in the field of tendon injuries or any other application explored. The problem often confronted is that in vitro release kinetics may differ from in vivo release kinetics, once the delivery device comes in contact with tissues and body fluids, where it is exposed to additional degradation by enzymes. Enzymes that are present at inflamed wound sites and found in plasma, by oxidation or hydrolysis, can affect the degradation rate of the material and, thus, influence the release profile from the device. Also, sterilisation methods, as part of in vivo procedures and regulations can affect the material degradation (Savaris et al., 2016) and bioactivity of the incorporated growth factors (Mainil-Varlet et al., 1997; Moioli et al., 2006). Furthermore, the stability and bioactivity of the released growth factor at the wound site can differ from the in vitro conditions.

\section{Fibrin-based delivery device}

In vitro, PDGF-BB has been shown to support proliferation and DNA synthesis, as described in detail in part A. Hence, accelerated wound healing is expected in vivo, which has been confirmed for a fibrin-based system. Moreover, PDGF-BB was shown to improve the gliding capacity, an aspect that can only be confirmed by in vivo experiments. This fibrin-based delivery system, where PDGF-BB is attached to heparin, which is itself electrostatically bound to a peptide acting as a bridge to fibrin (Fig. 5B) (Sakiyama-Elbert et al., 2008), was tested in a canine flexor tendon model (Thomopoulos et al., 2007) (Table 3). The intrasynovial flexor tendons of the forepaw were fully and transversely transected, sutured with an 8-strand suture and the defect was filled with the gel, acting as a delivery system. $100 \mathrm{ng}$ of PDGF-BB were incorporated into the delivery device and tendons were analysed histologically 7 and $14 \mathrm{~d}$ postoperatively. Cell density, proliferation, total DNA levels, reducible collagen crosslink levels and type I collagen expression were assessed. A clear beneficial effect was observed in comparison to the control group, where the dogs received the same transection, pocketing and suture without fibrin gel application. Cell density, proliferation and type I collagen expression were increased in PDGF-BB-treated specimens at both time points, compared to the control. Also, reducible collagen crosslinks were significantly increased $7 \mathrm{~d}$ postoperatively, which indicates that the PDGF-BBtreated tendons demonstrated accelerated healing; reducible crosslinks increased when the remodelling phase was entered. In contrast to these positively influenced parameters, the collagen organisation and the inflammatory reaction were similar in both groups, thus not affected by PDGF-BB. Moreover, with an increased dosage of $500 \mathrm{ng}$ of PDGF-BB, incorporated in the same delivery system, and increase in cell density, proliferation and type I collagen expression were detected $14 \mathrm{~d}$ post-operation and confirmed previous results (Thomopoulos et al., 2009).

This fibrin-based PDGF-BB delivery system was also evaluated 3 weeks post-surgery, in terms of gliding capacity (range of motion) and biomechanical strength (Gelberman et al., 2007). Interestingly, PDGFBB-treated specimen exhibited a higher range of motion. The rotations of the proximal interphalangeal (PIP) joint and the distal interphalangeal (DIP) joint were assessed, based on the differences between the flexed and extended positions. The DIP and PIP ranges of motion (ROMs) were significantly higher in the PDGF-BB group (around doubled ROMs). Besides its mitogenic effects, there is some evidence that PDGF-BB stimulates the biosynthesis of hyaluronan, one of the most studied and applied anti-adhesives (Meier Buergisser and Buschmann, 2015) and an important lubricant of the intrasynovial fluid in healthy tendons. Biosynthesis of hyaluronan, as a result of PDGF-BB application, has been reported for tenocytes (Thomopoulos et al., 2009), as well as for prostate smooth muscle cells (Pullen et al., 2001), cardiomyocytes (Hellman et al., 2010) and temporomandibular joint disc-derived cells (Hanaoka et al., 2006). The application at the wound site of a sustainable, releasing, PDGF-BB-loaded device, not only accelerated wound healing 1 and 2 weeks post-surgery (Thomopoulos et al., 2007), but also enhanced significantly the gliding of the tendons, as found 3 weeks post-intervention (Gelberman et al., 2007). In a subsequent study, where PDGF-BB amount was increased five-fold (to $500 \mathrm{ng}$ ) and the time point of tendons extraction was increased to 6 weeks, Thomopolous and co-workers confirmed the higher range of motion in the PDGF group, compared to control (Thomopoulos et al., 2009). Moreover, the increase in hyaluronic acid in PDGF group, compared 


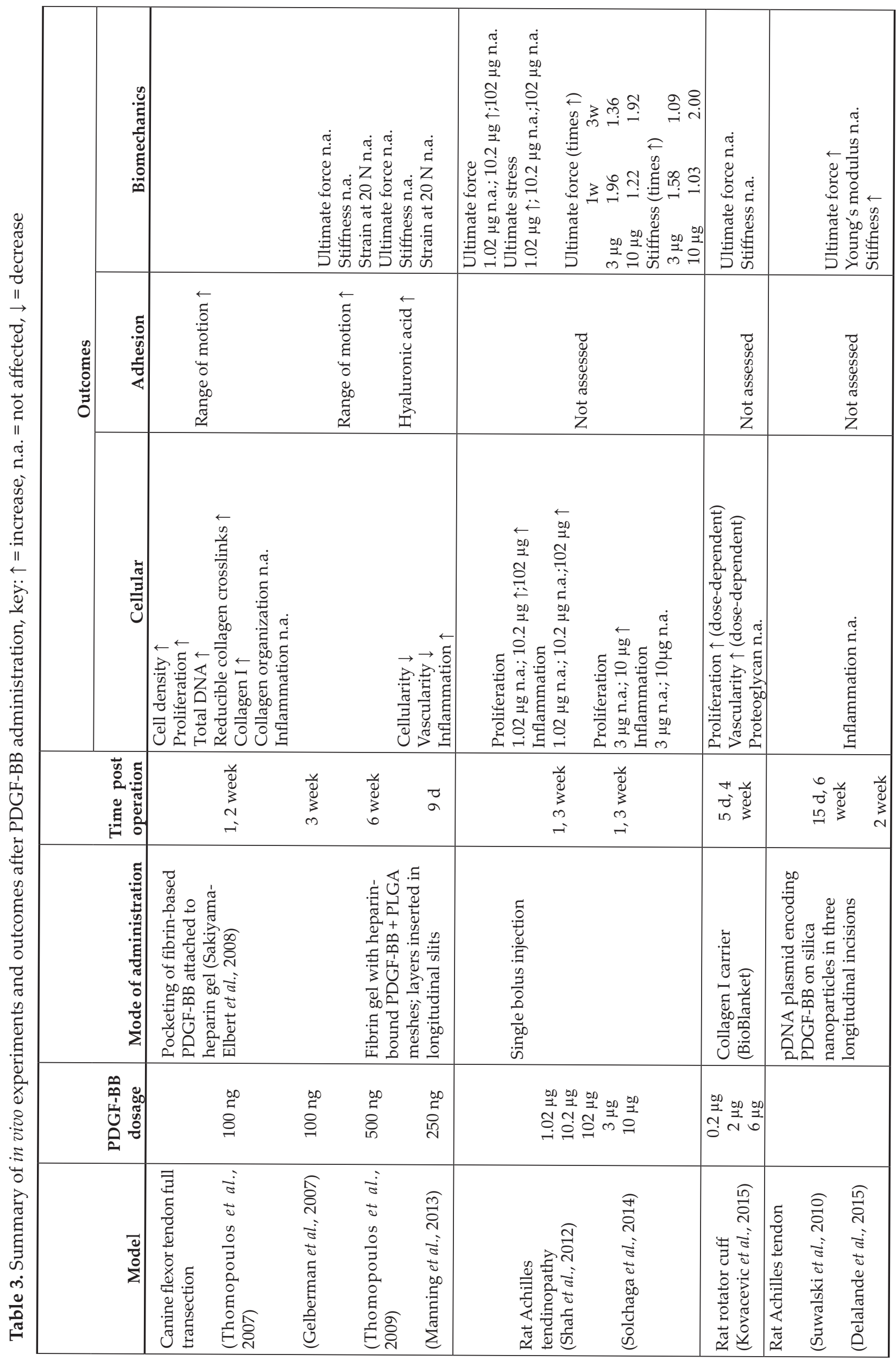


to control, supported one of the authors' hypotheses, namely that PDGF-BB stimulated the production of hyaluronic acid (Thomopoulos et al., 2009).

Although the fibrin-based delivery device (Sakiyama-Elbert et al., 2008) had been shown to promote tendon healing (Thomopoulos et al., 2007) and gliding capability, it did not enhance the biomechanical properties 3 weeks post-surgery, with peak forces, stiffness and strain at $20 \mathrm{~N}$ being very similar for PDGF-BB group and control group. The authors attributed this ineffectiveness to PDGF-BB dosage - the gel had been loaded with only $100 \mathrm{ng}$ of PDGF-BB (Gelberman et al., 2007). In a later study, although the loading amount of PDGF-BB in the fibrin-based matrix was increased to $500 \mathrm{ng}$ and the time point of post-operative examination extended to 6 weeks, the biomechanical properties were still similar with and without PDGF-BB delivery (Thomopoulos et al., 2009). Even though the sustained release of PDGF-BB from the corresponding matrix was detected in vitro over $10 \mathrm{~d}$ (Thomopoulos et al., 2007), in vivo conditions may differ in many aspects from in vitro conditions, affecting fibrin degradation, as well as, PDGF-BB release kinetics and stability at the wound site. Hence, promising findings in vitro have ultimately to be confirmed in vivo.

\section{Delivery device in combination with stem cells}

Although the fibrin-based system with PDGF-BB attached to heparin (Sakiyama-Elbert et al., 2008) allowed for an enhanced flexor tendon healing (Thomopoulos et al., 2007; Thomopoulos et al., 2009), the handling of the hydrogel, with its soft consistency, was difficult during surgical implantation. To overcome the rather difficult consistency, the hydrogel was layered with electrospun PLGA fibre meshes. A second potential improvement was the simultaneous seeding of adipose-derived stem cells (ASCs) (Manning et al., 2013). An alternating layered scaffold was constructed with PDGF-BB and ASCs incorporated in the heparin-fibrin delivery layers and with layers made of PLGA (no PDGF-BB, no cells). After a full transection of canine flexor tendons, longitudinally-oriented horizontal slits were created in the centre of each tendon stump and the layered scaffold was implanted and fixed by suture at the repair site. It was reported that the release of PDGF$\mathrm{BB}$ in vitro was $22 \%$ on the first day and progressed steadily to $71 \%$ by day 9 . In addition, in vivo, at the repair site, the fluorescently-labelled cells were still viable after $9 \mathrm{~d}$. Although the presence of ASCs might further enhance the flexor tendon healing, the layered scaffold was also implanted with PDGF-BB alone, incorporated in the fibrin-based layers (no ACSs). In terms of cellular response during early healing, it was found that the cellularity and vascularity in the cell-free scaffold with PDGF-BB were slightly decreased at day 9 post-operation, when compared to the repair-only group (only suture). In contrast, inflammatory cells, such as foreign body giant cells, poly-morphonuclear cells and monocytes, were slightly increased in the acellular PDGF-BB system (Manning et al., 2013), suggesting a mild immune response towards the scaffold material (PLGA). Hence, although acceleration of cell proliferation by PDGF-BB has been shown to be manifold in vitro, this example shows that total cell densities during the healing process change with time and, at certain time points after injury, may be decreased, compared to native densities - which is impossible to demonstrate in vitro. Moreover, in vivo, at the repair site, the impact of PDGF-BB on inflammatory cells and the relative abundance of macrophages, monocytes, foreign body giant cells may differ from single cell cultures, where the chemotactic effect of PDGF-BB on macrophages (Inaba et al., 1993), monocytes and neutrophils (Deuel et al., 1982) can be observed with a single focus on these cell types - regardless of the multiple orchestra of factors and cytokines released from all cell types present at the wound site. Again, we conclude that in vivo experiments are absolutely necessary to elucidate the mentioned issues.

\section{Single bolus injection}

As different enzymes may affect the stability and bioactivity of PDGF-BB in vivo, the outcomes for dosage's effect must be examined concisely. In a rat Achilles tendon model, it has been shown that lower dosages may positively affect biomechanical outcomes äat early time points, i.e. one week postoperation, while higher dosages have this effect only at later time points, i.e. 3 weeks. In this rat Achilles tendon model, tendinopathy was induced by collagenase, $7 \mathrm{~d}$ prior to PDGF-BB administration. When the healing tissue was analysed histologically for cellularity, collagen fibre orientation and density, inflammation and vascularisation, it was found that different amounts of single bolus applied at the wound site had different dose-dependent effects. Furthermore, biomechanical strength, 1 and 3 weeks post-administration, was also influenced by PDGF-BB (Shah et al., 2013).

When doses of 1.02, 10.2 and $102 \mu \mathrm{g}$ of PDGF were applied, the cell proliferation was significantly increased at 10.2 and $102 \mu \mathrm{g}$, but not at $1.02 \mu \mathrm{g}$ of PDGF. 3 weeks post-application, inflammatory reaction and vascularisation were significantly increased only at the highest dose (102 $\mu \mathrm{g}$ of PDGF). Furthermore, assessment of biomechanics revealed that only the highest dose group had significantly larger failure loads at 1 and 3 weeks, compared to the other treated groups - indicating a biphasic dosedependence and the need for an exact evaluation of the optimum growth factor amount (Shah et al., 2013).

Solchaga et al. (2014) also worked with a single injection of PDGF-BB. Either 3 or $10 \mu \mathrm{g}$ of PDGF-BB, dissolved in $30 \mu \mathrm{L}$ of PBS, were intra-tendon injected in a rat Achilles tendon model, where the tendinopathy was induced by collagenase. The proliferating cells were quantified in a histological section by proliferating cell nuclear antigen (PCNA) positive cell counting. It was found that cell proliferation was 
significantly increased, with $65 \%$ more proliferating cells, in the $10 \mu \mathrm{g}$ of PDGF-BB-group, compared to saline control. In terms of inflammatory reaction, no different effect was detected for both doses, when compared to the control.

In this tendinopathy model, biomechanical properties of the tendons were positively influenced 1 and 3 weeks post-administration and only at $10.2 \mu \mathrm{g}$ of PDGF. Other concentrations have not shown a significant difference compared to the normal untreated control (Shah et al., 2013). On the other hand, ultimate tensile stress was only significantly higher, compared to the other groups, in the $1.02 \mu \mathrm{g}$ of PDGF group. Such findings stress the importance of an appropriate dosage, which can be easily and exactly chosen when single bolus injections are used, but is a more delicate and difficult issue when growth factor delivery devices are used to release the factor in a controlled way. The beneficial effects in terms of biomechanics were reported also for a rat Achilles tendon tendinopathy model, where 3 or $10 \mu \mathrm{g}$ of PDGF-BB were applied intra-tendon as a single injection (Solchaga et al., 2014). Analysis post-surgery revealed that the ultimate loads were increased by factor of 1.96 and 1.36 for the $3 \mu$ g group and 1.22 and 1.92 for the $10 \mu \mathrm{g}$ group all at 7 and $21 \mathrm{~d}$ post-surgery, respectively. Similarly, stiffness increased by factors of 1.58 and 1.09 for the $3 \mu \mathrm{g}$ group and 1.03 and 2.00 for the $10 \mu \mathrm{g}$ group at 7 and $21 \mathrm{~d}$, respectively. It may be concluded that smaller amounts of PDGF-BB, such as $3 \mu \mathrm{g}$, enhance biomechanics in the first week, while larger amounts of PDGF-BB, such as $10 \mu \mathrm{g}$, lead to better biomechanical outcomes only later (as shown here for 3 weeks) (Solchaga et al., 2014).

\section{PDGF-BB adsorbed on collagen}

In a rat rotator cuff model, PDGF-BB was applied in three different dosages using a commercial collagen I scaffold (BioBlanket Surgical Mesh; Kensey Nash, Exton, PA, USA). Either 0.6, 2 or $6 \mu \mathrm{g}$ of PDGF-BB were dissolved in a sodium acetate buffer and small volumes of it were adsorbed on the scaffold immediately before surgical implantation (Kovacevic et al., 2015). Histological and biomechanical analyses were performed at 5 and $28 \mathrm{~d}$, respectively. Cellular proliferation, detected with PCNA immunohistochemical analysis at day 5, was found to be dose-dependent, with the highest number of actively dividing cells at the highest dosage of PDGF-BB. The same was found for the angiogenic response: the strongest staining was detected for the highest dosage of PDGF-BB, when analysed with Factor VIII immunohistochemistry. However, proteoglycan staining and collagen birefringence, both analysed $28 \mathrm{~d}$ post-surgery, did not reveal any difference between the PDGF-dosage groups, nor between the groups and the control, where a collagen scaffold without PDGF-BB was implanted (Kovacevic et al., 2015).

Although promising effects at the cellular level were found for this collagen delivery system, with
PDGF-BB adsorbed in different dosages, no beneficial effect were observed $28 \mathrm{~d}$ post-operation on the biomechanical outcome, when the delivery system was applied as a rat supraspinatus augmentation (Kovacevic et al., 2015). No significant differences were measured in ultimate load and stiffness, when the scaffolds loaded with $0.6,2.00$ or $6 \mu \mathrm{g}$ of PDGF-BB were compared to the pure scaffold.

\section{Non-viral PDGF-BB gene transfer}

Surface-modified silica nanoparticles (functionalisation with amino- and subsequently carboxylic-functional groups) were used as a vehicle for $\mathrm{pDNA}$ plasmid encoding PDGF-B gene (Suwalski et al., 2010). In a rat Achilles tendon model, three longitudinal incisions were made and $50 \mu \mathrm{L}$ of the pDNA/nanoparticle ( $2: 5)$ were injected into the middle incision. $15 \mathrm{~d}$ post-treatment, biomechanical measurements revealed that the gene transfer using these nanoparticles improved the ultimate load, while the Young's modulus was similar, when compared to the control. As silica may induce inflammatory reaction when used as an implant material (Lin et al., 2006), Suwalski and co-workers investigated this aspect as well. Histological analysis revealed no local inflammation nor necrosis, even when analysed after 6 weeks (Suwalski et al., 2010).

Another type of non-viral-based gene transfer vehicle, realised with liposomes, was developed and beneficially applied in a rat Achilles tendon model with triple longitudinal incisions used as tendon laceration. $50 \mu \mathrm{L}$ of liposomes, of two different compositions, containing $20 \mu \mathrm{g}$ of plasmids DNA encoding PDGF gene were slowly injected into the middle section of the Achilles tendon. $14 \mathrm{~d}$ postinjection, the PDGF group showed a stiffness of $83 \%$ compared to uninjured tendon, while the non-treated control only reached $72 \%$, indicating a beneficial in vivo effect at early time points during the healing process (Delalande et al., 2015).

\section{PDGF-BB coated sutures}

As an alternative to the delivery systems described above, Cummings et al. (2012) reported on a PDGFBB-coated Vicryl suture, applied in a rat Achilles tendon transection model. By dipping the sutures in either 0 (control), $0.3,3$ or $10 \mathrm{mg} \times \mathrm{mL}^{-1}$ of PDGF solutions, the authors could show the beneficial effect, 4 weeks post-operatively, of PDGF-BB-coated suture. The biomechanical properties increased in a dose-dependent manner and improved tissue remodelling with decreased tendon cross-sectional area and improved collagen organisation in the repaired tendons.

\section{Current limitations and future work}

PDGF-BB is well known for its mitotic, chemotactic and angiogenic activity (Anitua et al., 2012) and because of this, it is considered as a promising 
candidate for tendon repair. As it is FDA approved and used in clinical settings for other applications, no safety problems are expected to arise with its use for tendon repair (Paul et al., 2015; Solchaga et al., 2012; Ziyadeh et al., 2011). Many in vitro studies with tenocytes clearly demonstrate its biological properties (Raghavan et al., 2012; Zhao and Hadjiargyrou, 2011), while studies of its effects on the tendon progenitor stem cell population are still missing. On the other hand, most studies explored cell responses in 2D environment, while this can differ in 3D models (Antoni et al., 2015; Pampaloni et al., 2007) and can help bridge the gap with in vivo experimental outcomes. Even though there are some observations, systematic information is still missing on how PDGF$\mathrm{BB}$ alone, or in interplay with other growth factors, could affect specific tendon markers (tenomodulin, Scx, Mohawk etc.).

So far, in vitro experiments do not allow for direct correlations and conclusions when it comes to prediction of in vivo outcomes. In vivo models are necessary for determining its biological impact on biomechanical properties (Buschmann and Meier Buergisser, 2017) or tissue composition. Similarly, the effectiveness of any PDGF-BB delivery device, allowing for its sustained delivery over a longer period in in vitro conditions, accompanied with promising outcomes, can differ in vivo, potentially resulting in reduced effectiveness in aiding tendon repair. Two main parameters for in vivo effectiveness are dosage and time of application, which may be difficult to simulate in cell culture conditions or in three-dimensional cultures using tissue engineered constructs (Juncosa-Melvin et al., 2006). Low dosages ( $100 \mathrm{ng})$ of PDGF-BB delivered in vivo in a sustained manner enhanced cell proliferation, but did not show any beneficial impact on biomechanics (Thomopoulos et al., 2007). Only higher doses ( $500 \mathrm{ng}$ ) of PDGF$\mathrm{BB}$ delivered in the same way resulted in beneficial effects (Thomopoulos et al., 2009). On the other hand, when single bolus injections (Shah et al., 2013) or different scaffolds/carriers are used for delivery (Kovacevic et al., 2015), much larger amounts (1$10 \mu \mathrm{g})$ might be needed to have any effect on the biomechanics of the tendons. With the current studies suggesting higher dosages of PDGF-BB as promising, a systematic study in one in vivo model, with different delivery methods and dosages and the possibility to track the release profile of the growth factor in vivo is missing. These types of studies would offer valuable insights into the mechanism of release and what really plays an important role in improving the resulting biomechanical properties.

The proper time of application and delivery is the second important aspect that can affect the success of the biological therapy with PDGF-BB. Very early administration (immediate up to $3 \mathrm{~d}$ post-injury) in a single shot did not add any benefits to the healing process and might not be the correct approach. Ideally, PDGF-BB should be applied around 1 week post-laceration (Chan et al., 2006; Gulotta and Rodeo,
2009) by a single bolus injection. Even better, it could be incorporated in a delivery system that allows its sustained release to the wound site over the duration of at least two weeks. Delivery systems that partially degrade during the first week post-operation, leading to largest release of PDGF-BB after this period, could be considered as promising candidates for tendon rupture repair. However, careful and comprehensive degradation and integration studies of the delivery device in vivo, without any growth, factor should be initially performed. For example, the polymer DegraPol $^{\circledR}$, intended to be used as a PDGF-BB delivery device for tendon repair (Evrova et al., 2016), has been thoroughly investigated for its in vivo effects in terms of cellular response prior to PDGF-BB incorporation (Buschmann et al., 2013; Buschmann et al., 2015). Moreover, there is little to no knowledge about the half-life of delivered PDGF-BB at the wound site from the different devices or its half-life within the different biomaterials and devices. This can be an important parameter to be determined for establishing the effectiveness of any proposed delivery strategy and needs future research. Future studies should focus on standardised animal models to enable the comparison of different delivery devices, at best implanted in the same way into the same animal model. Moreover, methods, readouts and time points of post-operative analysis should be standardised to allow for a full and adequate comparison of different delivery strategies, dosages used or time points tested. Only data resulting from comparable in vivo experiments could be used to elucidate which strategy might be best to be transferred into clinical trials later. Unfortunately, so far, different research groups have focused on selected aspects, such as only biomechanical readouts, only inflammation or tissue remodelling etc., which renders the puzzle difficult to be fully solved.

Another focus of future work should be gaining more insight into mechanisms that might play a role in improved biomechanics or tissue organisation. A closer look at tissue remodelling at the wound site, what extracellular matrix components are present, as well as what tendon specific markers might be upregulated or downregulated during the treatment period with PDGF-BB, may offer knowledge as to how the healing might be affected and in turn how this can be used for better design of delivery devices or optimisation of application time.

\section{Conclusion}

Biological therapies after tendon ruptures or lacerations have many faces. Acceleration of the healing process with a true regeneration of the tendon tissue is a predominant desired aim. All cues leading to a faster cell infiltration to the wound site, with increased cell proliferation and accompanied with proper ECM remodelling are welcomed (Elliot and Giesen, 2013a; Elliot and Giesen, 2013b). Thus, the use 
of growth factors delivered at the injury site, either single or applied as a cocktail of many (Nourissat et al., 2013), provides a promising approach to support the tendon healing process. Different growth factors including TGF $\beta 1$, PDGF, VEGF and fibroblast growth factor-2 (FGF-2) have been explored for tendon repair and have shown mixed responses of the regenerated tendons in terms of biomechanical and histological outcomes. VEGF was shown to have deleterious effect on tendon healing due to MMP-3-supported angiogenesis, with inferior biomechanical properties of the tendons (Sahin et al., 2012). Local delivery of TGF $\beta 1$ was shown to improve the biomechanical and histological properties of the tendons (Halper, 2014; Majewski et al., 2012). However, TGF $\beta 1$ is a growth factor associated with complex biological signalling and scar and adhesion formation (Chang et al., 2000b; Galatz et al., 2006; Penn et al., 2012). Exogenous delivery of FGF-2 in a canine model did not result in improved biomechanical or molecular properties of the treated tendons (Thomopoulos et al., 2010b), on the other hand FGF-2 gene transfer has yielded more promising results (Tang et al., 2008). In comparison, and as summarised in this review, PDGF-BB with its clinical approval and biological properties represents a safe and promising growth factor to be applied as biological therapy in tendon rupture repair, administered either by bolus injection or incorporated in an implantable delivery device.

From the literature covered in this review and the observations existing so far, it can be concluded that from the available delivery strategies, a single bolus injection of $10 \mu \mathrm{g}$ of PDGF-BB one week post-operation (Shah et al., 2013) or a fibrin-based PDGF-BB delivery system loaded with much larger amounts than reported, e.g. $10 \mu \mathrm{g}$ instead of only $0.5 \mu \mathrm{g}$ (Thomopoulos et al., 2009), would probably be the most promising approaches. However, for its potential to be fully exploited, crucial aspects like dosage, time of application and delivery method need to be carefully considered, chosen and further investigated in one and same in vivo model, while looking at many readouts as possible including biomechanics, inflammation and tissue remodelling.

\section{Disclosure}

The authors confirm that there are no conflicts of interest.

\section{References}

Andia I, Maffulli N (2015) Use of platelet-rich plasma for patellar tendon and medial collateral ligament injuries: best current clinical practice. J Knee Surg 28: 11-17.

Andrae J, Gallini R, Betsholtz C (2008) Role of platelet-derived growth factors in physiology and medicine. Genes Dev 22: 1276-1312.
Anitua E, Sanchez M, De la Fuente M, Zalduendo MM, Orive G (2012) Plasma rich in growth factors (PRGF-Endoret) stimulates tendon and synovial fibroblasts migration and improves the biological properties of hyaluronic acid. Knee Surg Sports Traumatol Arthrosc 20: 1657-1665.

Anitua E, Sanchez M, Nurden AT, Zalduendo M, de la Fuente M, Azofra J, Andia I (2007) Reciprocal actions of platelet-secreted TGF-beta 1 on the production of VEGF and HGF by human tendon cells. Plast Reconstr Surg 119: 950-959.

Antoni D, Burckel H, Josset E, Noel G (2015) Three-dimensional cell culture: a breakthrough in vivo. Int J Mol Sci 16: 5517-5527.

Banes AJ, Tsuzaki M, Hu PQ, Brigman B, Brown T, Almekinders L, Lawrence WT, Fischer T (1995) PDGF-BB, IGF-I and mechanical load stimulate DNA synthesis in avian tendon fibroblasts in vitro. J Biomech 28: 1505-1513.

Barrientos S, Brem H, Stojadinovic O, Tomic-Canic M (2014) Clinical application of growth factors and cytokines in wound healing. Wound Repair Regen 22: 569-578.

Beredjiklian PK (2003) Biologic aspects of flexor tendon laceration and repair. J Bone Joint Surg 85A: 539-550.

Bi Y, Ehirchiou D, Kilts TM, Inkson CA, Embree MC, Sonoyama W, Li L, Leet AI, Seo B-M, Zhang L, Shi S, Young MF (2007) Identification of tendon stem/progenitor cells and the role of the extracellular matrix in their niche. Nat Med 13: 1219-1227.

Bissell L, Tibrewal S, Sahni V, Khan WS (2014) Growth factors and platelet rich plasma in anterior cruciate ligament reconstruction. Curr Stem Cell Res Ther 10: 19-25.

Borena BM, Martens A, Broeckx SY, Meyer E, Chiers K, Duchateau L, Spaas JH (2015) Regenerative skin wound healing in mammals: state-of-the-art on growth factor and stem cell based treatments. Cell Physiol Biochem 36: 1-23.

Brent AE, Braun T, Tabin CJ (2005) Genetic analysis of interactions between the somitic muscle, cartilage and tendon cell lineages during mouse development. Development 132: 515-528.

Brent AE, Tabin CJ (2004) FGF acts directly on the somitic tendon progenitors through the Ets transcription factors Pea3 and Erm to regulate scleraxis expression. Development 131: 3885-3896.

Briggs T, Arinzeh TL (2013) Examining the formulation of emulsion electrospinning for improving the release of bioactive proteins from electrospun fibers. J Biomed Mat Res Part A 102: 674684.

Briggs T, Matos J, Collins G, Arinzeh TL (2015) Evaluating protein incorporation and release in electrospun composite scaffolds for bone tissue engineering applications. J Biomed Mat Res Part A 103: 3117-3127.

Brooks PC, Clark RAF, Cheresh DA (1994) Requirement of vascular integrin alpha(5) beta(3) for angiogenesis. Science 264: 569-571. 
Buschmann J, Calcagni M, Meier Buergisser G, Bonavoglia E, Neuenschwander P, Milleret V, Giovanoli P (2015) Synthesis, characterization and histomorphometric analysis of cellular response to a new elastic DegraPol ${ }^{\circledR}$ polymer for rabbit Achilles tendon rupture repair. J Tissue Eng Regen Med 9: 584-594.

Buschmann J, Meier Buergisser G (2017) Biomechanics of tendons and ligaments tissue reconstruction and regeneration. Elsevier, United Kingdom: 1-330

Buschmann J, Meier Buergisser G, Bonavoglia E, Neuenschwander P, Milleret V, Giovanoli P, Calcagni M (2013) Cellular response of healing tissue to DegraPol tube implantation in rabbit Achilles tendon rupture repair: an in vivo histomorphometric study. J Tissue Eng Regen Med 7: 413-420.

Butler DL, Grood ES, Noyes FR, Zernicke RF (1978) Biomechanics of ligaments and tendons. Exerc Sport Sci Rev 6: 125-181.

Caliari SR, Harley BAC (2011) The effect of anisotropic collagen-GAG scaffolds and growth factor supplementation on tendon cell recruitment, alignment, and metabolic activity. Biomaterials 32: 5330-5340.

Castillo TN, Pouliot MA, Kim HJ, Dragoo JL (2011) Comparison of growth factor and platelet concentration from commercial platelet-rich plasma separation systems. Am J Sports Med 39: 266-271.

Chan BP, Fu SC, Qin L, Rolf C, Chan KM (2006) Supplementation-time dependence of growth factors in promoting tendon healing. Clin Orthop Relat Res 448: 240-247.

Chang J, Thunder R, Most D, Longaker MT, Lineaweaver WC (2000a) Studies in flexor tendon wound healing: neutralizing antibody to TGF-beta1 increases postoperative range of motion. Plast Reconstr Surg 105: 148-155.

Chang J, Tunder R, Most D, Longaker MT, Lineaweaver WC (2000b) Studies in flexor tendon wound healing: neutralizing antibody to TGF-beta1 increases postoperative range of motion. Plast Reconstr Surg 105: 148-155.

Chazaud B (2014) Macrophages: supportive cells for tissue repair and regeneration. Immunobiology 219: 172-178.

Chen CH, Cao Y, Wu YF, Bais AJ, Gao JS, Tang JB (2008) Tendon healing In vivo: gene expression and production of multiple growth factors in early tendon healing period. The J Hand Surg 33: 1834-1842.

Cheng Q, Komvopoulos K, Li S (2014) Plasmaassisted heparin conjugation on electrospun poly(1lactide) fibrous scaffolds. J Biomed Mat Res Part A 102: 1408-1414.

Chuen FS, Chuk CY, Ping WY, Nar WW, Kim HL, Ming CK (2004) Immunohistochemical characterization of cells in adult human patellar tendons. J Histochem Cytochem 52: 1151-1157.

Connizzo BK, Yannascoli SM, Soslowsky LJ (2013) Structure-function relationships of postnatal tendon development: a parallel to healing. Matrix Biol 32: 106-116.

Costa MA, Wu C, Pham BV, Chong AKS, Pham HM, Chang J (2006) Tissue engineering of flexor tendons: optimization of tenocyte proliferation using growth factor supplementation. Tissue Eng 12: 19371943.

Cummings SH, Grande DA, Hee CK, Kestler HK, Roden CM, Shah NV, Razzano P, Dines DM, Chahine NO, Dines JS (2012) Effect of recombinant human platelet-derived growth factor-BB-coated sutures on Achilles tendon healing in a rat model: a histological and biomechanical study. J Tissue Eng 3: 1-9.

de Almeida AM, Demange MK, Sobrado MF, Rodrigues MB, Pedrinelli A, Hernandez AJ (2012) Patellar tendon healing with platelet-rich plasma a prospective randomized controlled trial. Am J Sports Med 40: 1282-1288.

de Mos M, Koevoet WJLM, Jahr H, Verstegen MMA, Heijboer MP, Kops N, Van Leeuwen JPTM, Weinans H, Verhaar JAN, van Osch GJVM (2007) Intrinsic differentiation potential of adolescent human tendon tissue: an in vitro cell differentiation study. BMC Musculoskelet Disord 8: 1-12.

de Vos RJ, van Veldhoven PLJ, Moen MH, Weir A, Tol JL, Maffulli N (2010) Autologous growth factor injections in chronic tendinopathy: a systematic review. Br Med Bull 95: 63-77.

Delalande A, Gosselin M-P, Suwalski A, Guilmain W, Leduc C, Berchel M, Jaffres P-A, Baril P, Midoux P, Pichon C (2015) Enhanced Achilles tendon healing by fibromodulin gene transfer. Nanomedicine 11: 1735-1744.

DeMali KA, Balciunaite E, Kazlauskas A (1999) Integrins enhance platelet-derived growth factor (PDGF)-dependent responses by altering the signal relay enzymes that are recruited to the PDGF beta receptor. J Biol Chem 274: 19551-19558.

Deuel TF, Kawahara RS, Mustoe TA, Pierce GF (1991) Growth-factors and wound-healing - plateletderived growth-factor as a model cytokine. Annu Rev Med 42: 567-584.

Deuel TF, Senior RM, Huang JS (1982) Chemotaxis of monocytes and neutrophils to platelet-derived growth-factor. J Clin Invest 69: 1046-1049.

Docheva D, Mueller SA, Majewski M, Evans CH (2015) Biologics for tendon repair. Adv Drug Del Rev 84: 222-239.

Edom-Vovard F, Schuler B, Bonnin MA, Teillet MA, Duprez D (2002) Fgf4 positively regulates scleraxis and tenascin expression in chick limb tendons. Dev Biol 247: 351-366.

Elliot D, Giesen T (2013a) Avoidance of unfavourable results following primary flexor tendon surgery. Indian J Plast Surg 46: 312-324.

Elliot D, Giesen T (2013b) Primary flexor tendon surgery: the search for a perfect result. Hand Clin 29: 191-206.

Eppley BL, Woodell JE, Higgins J (2004) Platelet quantification and growth factor analysis from 
platelet-rich plasma: implications for wound healing. Plast Reconstr Surg 114: 1502-1508.

Evrova O, Houska J, Welti M, Bonavoglia E, Calcagni M, Giovanoli P, Vogel V, Buschmann J (2016) Bioactive, elastic, and biodegradable emulsion electrospun degraPol tube delivering PDGF-BB for tendon rupture repair. Macromol Biosci 16: 10481063.

Fenwick SA, Hazleman BL, Riley GP (2002) The vasculature and its role in the damaged and healing tendon. Arthritis Res 4: 252-260.

Foster TE, Puskas BL, Mandelbaum BR, Gerhardt MB, Rodeo SA (2009) platelet-rich plasma from basic science to clinical applications. Am J Sports Med 37: 2259-2272.

Galatz LM, Gerstenfeld L, Heber-Katz E, Rodeo SA (2015) Tendon regeneration and scar formation: the concept of scarless healing. J Orthop Res 33: 823-831.

Galatz LM, Sandell LJ, Rothermich SY, Das R, Mastny A, Havlioglu N, Silva MJ, Thomopoulos S (2006) Characteristics of the rat supraspinatus tendon during tendon-to-bone healing after acute injury. J Orthop Res 24: 541-550.

Gelberman RH, Thomopoulos S, Sakiyama-Elbert SE, Das R, Silva MJ (2007) The early effects of sustained platelet-derived growth factor administration on the functional and structural properties of repaired intrasynovial flexor tendons: an in vivo biomechanic study at 3 weeks in canines. J Hand Surg-Am Vol 32A: 373-379.

Giusti B, Pepe G (2016) Fibrillins in tendon. Front Aging Neurosci 8: 237.

Glass ZA, Schiele NR, Kuo CK (2014) Informing tendon tissue engineering with embryonic development. J Biomech 47: 1964-1968.

Grant TM, Thompson MS, Urban J, Yu J (2013) Elastic fibres are broadly distributed in tendon and highly localized around tenocytes. J Anat 222: 573579.

Guan R, Sun XL, Hou SJ, Wu PY, Chaik of EL (2004) A glycopolymer chaperone for fibroblast growth factor-2. Bioconjug Chem 15: 145-151.

Gulotta LV, Rodeo SA (2009) Growth factors for rotator cuff repair. Clin Sports Med 28: 13-23.

Halper J (2014) Advances in the use of growth factors for treatment of disorders of soft tissues. In: Progress in heritable soft connective tissue diseases. Adv Exp Med Biol 802: 59-76.

Hanaoka K, Tanaka E, Takata T, Miyauchi M, Aoyama J, Kawai N, Dalla-Bona DA, Yamano E, Tanne K (2006) Platelet-derived growth factor enhances proliferation and matrix synthesis of temporomandibular joint disc-derived cells. Angle Orthod 76: 486-492.

Harwood FL, Goomer RS, Gelberman RH, Silva MJ, Amiel D (1999) Regulation of alpha v beta 3 and alpha 5 beta 1 integrin receptors by basic fibroblast growth factor and platelet-derived growth factor-BB in intrasynovial flexor tendon cells. Wound Repair Regen 7: 381-388.
Haupt JL, Donnelly BP, Nixon AJ (2006) Effects of platelet-derived growth factor-BB on the metabolic function and morphologic features of equine tendon in explant culture. Am J Vet Res 67: 1595-1600.

Hee CK, Dines JS, Solchaga LA, Shah VR, Hollinger JO (2012) Regenerative tendon and ligament healing: opportunities with recombinant human plateletderived growth factor BB-homodimer. Tissue Eng Part B 18: 225-234.

Heldin CH, Westermark B (1999) Mechanism of action and in vivo role of platelet-derived growth factor. Physiol Rev 79: 1283-1316.

Hellman U, Malm L, Ma LP, Larsson G, Morner $\mathrm{S}$, Fu M, Engstrom-Laurent A, Waldenstrom A (2010) Growth factor PDGF-BB stimulates cultured cardiomyocytes to synthesize the extracellular matrix component hyaluronan. PLoS One 5: e14393.

Hennink WE, Feijen J, Ebert CD, Kim SW (1983) Covalently bound conjugates of albumin and heparin - synthesis, fractionation and characterization. Thromb Res 29: 1-13.

Hodivala-Dilke K (2008) $\alpha v \beta 3$ integrin and angiogenesis: a moody integrin in a changing environment. Curr Opin Cell Biol 20: 514-519.

Hooley CJ, Cohen RE (1979) Model for the creel behaviour of tendon. Int J Biol Macromol 1: 123-132.

Howard D, Shepherd JH, Kew SJ, Hernandez P, Ghose S, Wardale JA, Rushton N (2014) Release of growth factors from a reinforced collagen GAG matrix supplemented with platelet rich plasma: influence on cultured human meniscal cells. J Orthop Res 32: 273-278.

Hsieh C-F, Alberton P, Loffredo-Verde E, Volkmer E, Pietschmann M, Mueller P, Schieker M, Docheva D (2016) Scaffold-free scleraxis-programmed tendon progenitors aid in significantly enhanced repair of full-size Achilles tendon rupture. Nanomedicine 11: 1153-1167.

Hsu C, Chang J (2004) Clinical implications of growth factors in flexor tendon wound healing. The J Hand Surg 29: 551-563.

Inaba T, Shimano H, Gotoda T, Harada K, Shimada M, Ohsuga J, Watanabe Y, Kawamura M, Yazaki Y, Yamada N (1993) Expression of platelet-derived growth-factor-beta receptor on human monocytederived macrophages and effects of platelet-derived growth-factor BB dimer on the cellular function. J Biol Chem 268: 24353-24360.

James MF, Beauchamp RL, Manchanda N, Kazlauskas A, Ramesh V (2004) A NHERF binding site links the betaPDGFR to the cytoskeleton and regulates cell spreading and migration. J Cell Sci 117: 2951-2961.

James R, Kesturu G, Balian G, Chhabra AB (2008) Tendon: biology, biomechanics, repair, growth factors, and evolving treatment options. J Hand SurgAm Vol 33A: 102-112.

Jeong DU, Lee CR, Lee JH, Pak J, Kang LW, Jeong BC, Lee SH (2014) Clinical applications of platelet-rich plasma in patellar tendinopathy. Biomed Res Int: 249498. 
Jiang H, Wang L, Zhu K (2014) Coaxial electrospinning for encapsulation and controlled release of fragile water-soluble bioactive agents. J Control Release 193: 296-303.

Juncosa-Melvin N, Boivin GP, Galloway MT, Gooch C, West JR, Butler DL (2006) Effects of cellto-collagen ratio in stem cell-seeded constructs for Achilles tendon repair. Tissue Eng 12: 681-689.

Juneja SC, Schwarz EM, O'Keefe RJ, Awad HA (2013) Cellular and molecular factors in flexor tendon repair and adhesions: a histological and gene expression analysis. Connect Tissue Res 54: 218-226.

Kajikawa Y, Morihara T, Watanabe N, Sakamoto H, Matsuda K-I, Kobayash M, Oshima Y, Yoshida A, Kawata M, Kubo T (2007) GFP chimeric models exhibited a biphasic pattern of mesenchymal cell invasion in tendon healing. J Cell Physiol 210: 684-691.

Kannus P (2000) Structure of the tendon connective tissue. Scand J Med Sci Sports 10: 312-320.

Kevy SV, Jacobson MS (2004) Comparison of methods for point of care preparation of autologous platelet gel. J Extra-corp Tech 36: 28-35.

Kielty CM, Sherratt MJ, Shuttleworth CA (2002) Elastic fibres. J Cell Sci 115: 2817-2828.

Klein MB, Yalamanchi N, Pham H, Longaker MT, Chang J (2002) Flexor tendon healing in vitro: effects of TGF-beta on tendon cell collagen production. J Hand Surg-Am Vol 27A: 615-620.

Kovacevic D, Gulotta LV, Ying L, Ehteshami JR, Deng X-H, Rodeo SA (2015) rhPDGF-BB promotes early healing in a rat rotator cuff repair model. Clin Orthop Relat Res 473: 1644-1654.

Kuo CK, Petersen BC, Tuan RS (2008) Spatiotemporal protein distribution of TGF-betas, their receptors, and extracellular matrix molecules during embryonic tendon development. Dev Dyn 237: 1477-1489.

Langer R (1990) New methods for drug delivery. Science 249: 1527-1533.

Lee J, Yoo JJ, Atala A, Lee SJ (2012a) Controlled heparin conjugation on electrospun poly(epsiloncaprolactone)/gelatin fibers for morphologydependent protein delivery and enhanced cellular affinity. Acta Biomater 8: 2549-2558.

Lee J, Yoo JJ, Atala A, Lee SJ (2012b) The effect of controlled release of PDGF-BB from heparinconjugated electrospun PCL/gelatin scaffolds on cellular bioactivity and infiltration. Biomaterials 33: 6709-6720.

Li H, Zhao CG, Wang ZX, Zhang H, Yuan XY, Kong DL (2010) Controlled release of PDGF-bb by coaxial electrospun dextran/poly(L-lactide-coepsilon-caprolactone) fibers with an ultrafine core/ shell structure. J Biomat Sci-Pol Ed 21: 803-819.

Liao IC, Chew SY, Leong KW (2006) Aligned core-shell nanofibers delivering bioactive proteins. Nanomedicine 1: 465-471.

Lin TW, Cardenas L, Soslowsky LJ (2004) Biomechanics of tendon injury and repair. J Biomech 37: 865-877.
Lin W, Huang Y-w, Zhou X-D, Ma Y (2006) In vitro toxicity of silica nanoparticles in human lung cancer cells. Toxicol Appl Pharmacol 217: 252-259.

Lomas AJ, Ryan CNM, Sorushanova A, Shologu N, Sideri AI, Tsioli V, Fthenakis GC, Tzora A, Skoufos I, Quinlan LR, O'Laighin G, Mullen AM, Kelly JL, Kearns S, Biggs M, Pandit A, Zeugolis DI (2015) The past, present and future in scaffold-based tendon treatments. Adv Drug Del Rev 84: 257-277.

Lorda-Diez CI, Montero JA, Martinez-Cue C, Garcia-Porrero JA, Hurle JM (2009) Transforming growth factors beta coordinate cartilage and tendon differentiation in the developing limb mesenchyme. J Biol Chem 284: 29988-29996.

Lui PPY (2013) Identity of tendon stem cells - how much do we know?. J Cell Mol Med 17: 55-64.

Lui PPY, Chan KM (2011) Tendon-Derived Stem Cells (TDSCs): From basic science to potential roles in tendon pathology and tissue engineering applications. Stem Cell Rev Rep 7: 883-897.

Lynch SE, Nixon JC, Colvin RB, Antoniades HN (1987) Role of platelet-derived growth-factor in wound-healing - synersgistic effects with other growth-factors. Proc Natl Acad Sci USA 84: 7696-7700.

Lyon M, Rushton G, Gallagher JT (1997) The interaction of the transforming growth factor-betas with heparin/heparan sulfate is isoform-specific. J Biol Chem 272: 18000-18006.

Ma C, Hernandez MA, Kirkpatrick VE, Liang L-J, Nouvong AL, Gordon IL (2015) Topical plateletderived growth factor $v$ s. placebo therapy of diabetic foot ulcers offloaded with windowed casts: a randomized, controlled trial. Wounds 27: 83-91.

Mainil-Varlet P, Curtis R, Gogolewski S (1997) Effect of in vivo and in vitro degradation on molecular and mechanical properties of various low-molecularweight polylactides. J Biomed Mater Res 36: 360-380.

Majewski M, Porter RM, Betz OB, Betz VM, Clahsen H, Fluckiger R, Evans CH (2012) Improvement of tendon repair using muscle grafts transduced with TGF-beta1 cDNA. Eur Cell Mater 23: 94-101.

Mangrulkar RS, Ono M, Ishikawa M, Takashima S, Klagsbrun M, Nowak RA (1995) Isolation and characterization of heparin-binding growth-factors in human lyomyomas and normal myometrium. Biol Reprod 53: 636-646.

Manning CN, Schwartz AG, Liu W, Xie J, Havlioglu N, Sakiyama-Elbert SE, Silva MJ, Xia Y, Gelberman RH, Thomopoulos S (2013) Controlled delivery of mesenchymal stem cells and growth factors using a nanofiber scaffold for tendon repair. Acta Biomater 9: 6905-6914.

Marques LF, Stessuk T, Cherici Camargo IC, Sabeh Junior N, Dos Santos L, Ribeiro-Paes JT (2015) Platelet-rich plasma (PRP): methodological aspects and clinical applications. Platelets 26: 101-113.

Meier Buergisser G, Calcagni M, Muller A, Bonavoglia E, Fessel G, Snedeker JG, Giovanoli P, Buschmann J (2014) Prevention of peritendinous adhesions using an electrospun DegraPol polymer 
tube: a histological, ultrasonographic, and biomechanical study in rabbits. Biomed Res Int: 656240.

Meier Buergisser GM, Buschmann J (2015) History and performance of implant materials applied as peritendinous antiadhesives. J Biomed Mat Res Part B 103: 212-228.

Mikic B, Bierwert L, Tsou D (2006) Achilles tendon characterization in GDF-7 deficient mice. J Orthop Res 24: 831-841.

Milz S, Ockert B, Putz R (2009) Tenocytes and the extracellular matrix - a reciprocal relationship. Orthopade 38: 1071-1079.

Moioli EK, Hong LIU, Guardado J, Clark PA, Mao JJ (2006) Sustained release of TGF $\beta 3$ from PLGA microspheres and its effect on early osteogenic differentiation of human mesenchymal stem cells. Tissue Eng 12: 537-546.

Molloy T, Wang Y, Murrell GAC (2003) The roles of growth factors in tendon and ligament healing. Sports Med 33: 381-394.

Murray MM, Fleming BC (2013) Biology of anterior cruciate ligament injury and repair: Kappa delta ann doner vaughn award paper 2013. J Orthop Res 31: 1501-1506.

Murray MM, Martin SD, Martin TL, Spector M (2000) Histological changes in the human anterior cruciate ligament after rupture. J Bone Joint Surg Am 82-A: 1387-1397.

Murray MM, Spindler KP, Ballard P, Welch TP, Zurakowski D, Nanney LB (2007) Enhanced histologic repair in a central wound in the anterior cruciate ligament with a collagen-platelet-rich plasma scaffold. J Orthop Res 25: 1007-1017.

Nikolidakis D, Jansen JA (2008) Biology of plateletrich plasma and its application in oral surgery: literature review. Tissue Eng Part B 14: 249-258.

Nordin M, Lorenz T, Campello M (2001) Biomechanics of tendons and ligaments. In: Basic biomechanics of the musculoskeletal system. Wilkins LWa edition, London: 102-125.

Nourissat G, Berenbaum F, Duprez D (2015) Tendon injury: from biology to tendon repair. Nat Rev Rheumatol 11: 223-233.

Nourissat G, Houard X, Sellam J, Duprez D, Berenbaum F (2013) Use of autologous growth factors in aging tendon and chronic tendinopathy. Front Biosci E5: 911-921.

Oakes BW (2008)Tendons and ligaments. In: Rehabilitation of sports injuries: scientific basis. Blackwell Science: 28-98.

Pampaloni F, Reynaud EG, Stelzer EHK (2007) The third dimension bridges the gap between cell culture and live tissue. Nat Rev Mol Cell Biol 8: 839-845.

Paul G, Zachrisson O, Varrone A, Almqvist P, Jerling M, Lind G, Rehncrona S, Linderoth B, Bjartmarz H, Shafer LL, Coffey R, Svensson M, Mercer KJ, Forsberg A, Halldin C, Svenningsson P, Widner H, Frisen J, Palhagen S, Haegerstrand A (2015) Safety and tolerability of intracerebroventricular PDGF-BB in Parkinson's disease patients. J Clin Invest 125: 1339-1346.

Paxton JZ, Hagerty P, Andrick JJ, Baar K (2012) Optimizing an intermittent stretch paradigm using ERK1/2 phosphorylation results in increased collagen synthesis in engineered ligaments. Tissue Eng Part A 18: $277-284$.

Penn JW, Grobbelaar AO, Rolfe KJ (2012) The role of the TGF- $\beta$ family in wound healing, burns and scarring: a review. Int J Burns Trauma 2: 18-28.

Pierce GF, Mustoe TA, Altrock BW, Deuel TF, Thomason A (1991) Role of platelet-derived growthfactor in wound-healing. J Cell Biochem 45: 319-326.

Pierce GF, Mustoe TA, Lingelbach J, Masakowski VR, Griffin GL, Senior RM, Deuel TF (1989) Plateletderived growth factor and transforming growth factor-beta enhabce tissue-repair activities by unique mechanisms. J Cell Biol 109: 429-440.

Pins GD, Christiansen DL, Patel R, Silver FH (1997) Self-assembly of collagen fibers. Influence of fibrillar alignment and decorin on mechanical properties. Biophys J 73: 2164-2172.

Pryce BA, Watson SS, Murchison ND, Staverosky JA, Dunker N, Schweitzer R (2009) Recruitment and maintenance of tendon progenitors by TGFbeta signaling are essential for tendon formation. Development 136: 1351-1361.

Pullen MA, Thomas K, Wu HL, Nambi P (2001) Stimulation of hyaluronan synthetase by plateletderived growth factor $\mathrm{bb}$ in human prostate smooth muscle cells. Pharmacology 62: 103-106.

Qiu Y, Wang X, Zhang Y, Carr AJ, Zhu L, Xia Z, Sabokbar A (2014) Development of a refined tenocyte expansion culture technique for tendon tissue engineering. J Tissue Eng Regen Med 8: 955-962.

Raghavan SS, Woon CYL, Kraus A, Megerle K, Hung P, Chang J (2012) Optimization of human tendon tissue engineering: synergistic effects of growth factors for use in tendon scaffold repopulation. Plast Reconstr Surg 129: 479-489.

Regent M, Planus E, Bouin AP, Bouvard D, Brunner M, Faurobert E, Millon-Fremillon A, Block MR, Albiges-Rizo C (2011) Specificities of beta(1) integrin signaling in the control of cell adhesion and adhesive strength. Eur J Cell Biol 90: 261-269.

Riley G (2004) The pathogenesis of tendinopathy. A molecular perspective. Rheumatology 43: 131-142.

Rim NG, Shin CS, Shin H (2013) Current approaches to electrospun nanofibers for tissue engineering. Biomedical Materials 8: 014102-014116.

Robinson SN, Talmadge JE (2002) Sustained release of growth factors. In Vivo 16: 535-540.

Sahin H, Tholema N, Petersen W, Raschke M, J., Stange R (2012) Impaired biomechanical properties correlate with neoangiogenesis as well as VEGF and MMP-3 expression during rat patellar tendon healing. J Orthop Res 30: 1952-1957.

Sakiyama-Elbert SE, Das R, Gelberman RH, Harwood F, Amiel D, Thomopoulos S (2008) Controlled-release kinetics and biologic activity of 
platelet-derived growth factor-BB for use in flexor tendon repair. J Hand Surg-Am 33A: 1548-1557.

Sakiyama-Elbert SE, Hubbell JA (2000a) Controlled release of nerve growth factor from a heparincontaining fibrin-based cell ingrowth matrix. J Control Release 69: 149-158.

Sakiyama-Elbert SE, Hubbell JA (2000b) Development of fibrin derivatives for controlled release of heparin-binding growth factors. J Control Release 65: 389-402.

Savaris M, dos Santos V, Brandalise RN (2016) Influence of different sterilization processes on the properties of commercial poly(lactic acid). Mat Sci Eng C 69: 661-667.

Schaer MO, Diaz-Romero J, Kohl S, Zumstein MA, Nesic D (2015) Platelet-rich concentrates differentially release growth factors and induce cell migration in vitro. Clin Orthop Relat Res 473: 1635-1643.

Schweitzer R, Chyung JH, Murtaugh LC, Brent AE, Rosen V, Olson EN, Lassar A, Tabin CJ (2001) Analysis of the tendon cell fate using scleraxis, a specific marker for tendons and ligaments. Development 128: 3855-3866.

Scott A, Sampaio A, Abraham T, Duronio C, Underhill TM (2011) Scleraxis expression is coordinately regulated in a murine model of patellar tendon injury. J Orthop Res 29: 289-296.

Shah V, Bendele A, Dines JS, Kestler HK, Hollinger JO, Chahine NO, Hee CK (2013) Dose-response effect of an intra-tendon application of recombinant human platelet-derived growth factor-BB (rhPDGF-BB) in a rat Achilles tendinopathy model. J Orthop Res 31: 413-420.

Sharma P, Maffulli N (2006) Biology of tendon injury: healing, modeling and remodeling. J Musculoskeletal Neuronal Interact 6: 181-190.

Siegbahn A, Hammacher A, Westermark B, Heldin CH (1990) Differential-effects of the various isoforms of platelet-derived growth-factor on chemotaxis of fibroblasts, monocytes, and granulocytes. J Clin Invest 85: 916-920.

Singh P, Suresh DK (2012) Clinical evaluation of GEM $21 S^{\circledR}$ and a collagen membrane with a coronally advanced flap as a root coverage procedure in the treatment of gingival recession defects: a comparative study. J Indian Soc Periodontol 16: 577-583.

Smiell JM, Wieman TJ, Steed DL, Perry BH, Sampson AR, Schwab BH (1999) Efficacy and safety of becaplermin (recombinant human platelet-derived growth factor-BB) in patients with nonhealing, lower extremity diabetic ulcers: a combined analysis of four randomized studies. Wound Repair Regen 7: 335-346.

Solchaga LA, Bendele A, Shah V, Snel LB, Kestler HK, Dines JS, Hee CK (2014) Comparison of the effect of intra-tendon applications of recombinant human platelet-derived growth factor-BB, platelet-rich plasma, steroids in a rat Achilles tendon collagenase model. J Orthop Res 32: 145-150.

Solchaga LA, Hee CK, Roach S, Snel LB (2012) Safety of recombinant human platelet-derived growth factor-BB in Augment ${ }^{\mathbb{B}}$ bone graft. J Tissue Eng 3: 1-6.
Spindler KP, Nanney LB, Davidson JM (1995) Proliferative responsed to platelet-derived growthfactor in young and old rat patellar tendon. Connect Tissue Res 31: 171-177.

Sproul EP, Argraves WS (2013) A cytokine axis regulates elastin formation and degradation. Matrix Biol 32: 86-94.

Sun B, Chen B, Zhao Y, Sun W, Chen K, Zhang J, Wei Z, Xiao Z, Dai J (2009) Crosslinking heparin to collagen scaffolds for the delivery of human plateletderived growth factor. J Biomed Mat Res Part B 91B: 366-372.

Suwalski A, Dabboue H, Delalande A, Bensamoun SF, Canon F, Midoux P, Saillant G, Klatzmann D, Salvetat J-P, Pichon C (2010) Accelerated Achilles tendon healing by PDGF gene delivery with mesoporous silica nanoparticles. Biomaterials 31: 5237-5245.

Tallquist M, Kazlauskas A (2004) PDGF signaling in cells and mice. Cytokine Growth Factor Rev 15: 205-213.

Tang JB (2005) Clinical outcomes associated with flexor tendon repair. Hand Clin 21: 199-210.

Tang JB, Cao Y, Zhu B, Xin K-Q, Wang XT, Liu PY (2008) Adeno-associated virus-2-mediated bFGF gene transfer to digital flexor tendons significantly increases healing strength. J Bone Joint Surg 90A: 1078-1089.

Thakkar D, Grant TM, Hakimi O, Carr AJ (2014) Distribution and expression of type VI collagen and elastic fibers in human rotator cuff tendon tears. Connect Tissue Res 55: 397-402.

Thomopoulos S, Das R, Sakiyama-Elbert S, Silva MJ, Charlton N, Gelberman RH (2010a) bFGF and PDGF-BB for tendon repair: controlled release and biologic activity by tendon fibroblasts in vitro. Ann Biomed Eng 38: 225-234.

Thomopoulos S, Das R, Silva MJ, Sakiyama-Elbert S, Harwood FL, Zampiakis E, Kim HM, Amiel D, Gelberman RH (2009) Enhanced flexor tendon healing through controlled delivery of PDGF-BB. J Orthop Res 27: 1209-1215.

Thomopoulos S, Harwood FL, Silva MJ, Amiel D, Gelberman RH (2005) Effect of several growth factors on canine flexor tendon fibroblast proliferation and collagen synthesis in vitro. J Hand Surg-Am Vol 30A: 441-447.

Thomopoulos S, Kim M, Das R, Silva MJ, Sakiyama-Elbert S, Amiel D, Gelberman RH (2010b) The effects of exogenous basic fibroblast growth factor on intrasynovial flexor tendon healing in a canine model. J Bone Joint Surg Am 92: 2285-2293.

Thomopoulos S, Zaegel M, Das R, Harwood FL, Silva MJ, Amiel D, Sakiyama-Elbert S, Gelberman RH (2007) PDGF-BB released in tendon repair using a novel delivery system promotes cell proliferation and collagen remodeling. J Orthop Res 25: 1358-1368.

Tzeng DY, Deuel TF, Huang JS, Baehner RL (1985) Platelet-derived growth-factor promotes human peripheral monocyte activation. Blood 66: 179-183.

Vahabi S, Torshabi M, Nejad AE (2016) In vitro comparison of the efficacy of TGF-beta 1 and PDGF- 
$\mathrm{BB}$ in combination with freeze-dried bone allografts for induction of osteogenic differentiation in MG-63 osteoblast-like cells. J Mater Sci Mater Med 27: 1-11.

Veevers-Lowe J, Ball SG, Shuttleworth A, Kielty CM (2011) Mesenchymal stem cell migration is regulated by fibronectin through alpha5beta1integrin-mediated activation of PDGFR-beta and potentiation of growth factor signals. J Cell Sci 124: 1288-1300.

Vetrano M, Castorina A, Vulpiani MC, Baldini R, Pavan A, Ferretti A (2013) Platelet-rich plasma versus focused shock waves in the treatment of jumper's knee in athletes. Am J Sports Med 41: 795-803.

Wieman TJ, Smiell JM, Su Y (1998) Efficacy and safety of a topical gel formulation of recombinant human platelet-derived growth factor-BB (becaplermin) in patients with chronic neuropathic diabetic ulcers. A phase III randomized placebocontrolled double-blind study. Diabetes Care 21: 822-827.

Wissink MJB, Beernink R, Pieper JS, Poot AA, Engbers GHM, Beugeling T, van Aken WG, Feijen J (2001) Binding and release of basic fibroblast growth factor from heparinized collagen matrices. Biomaterials 22: 2291-2299.

Wissink MJB, Beernink R, Poot AA, Engbers GHM, Beugeling T, van Aken WG, Feijen J (2000) Improved endothelialization of vascular grafts by local release of growth factor from heparinized collagen matrices. J Control Release 64: 103-114.

Wong MWN, Tang YYN, Lee SKM, Fu BSC, Chan BP, Chan CKM (2003) Effect of dexamethasone on cultured human tenocytes and its reversibility by platelet-derived growth factor. J Bone Joint Surg 85A: 1914-1920.

Wuergler-Hauri CC, Dourte LM, Baradet TC, Williams GR, Soslowsky LJ (2007) Temporal expression of 8 growth factors in tendon-to-bone healing in a rat supraspinatus model. J Shoulder Elbow Surg 16: 198S-203S.

Yoshikawa Y, Abrahamsson SO (2001) Doserelated cellular effects of platelet-derived growth factor-BB differ in various types of rabbit tendons in vitro. Acta Orthop Scand 72: 287-292.

Younesi M, Donmez BO, Islam A, Akkus O (2016) Heparinized collagen sutures for sustained delivery of PDGF-BB: delivery profile and effects on tendonderived cells in-vitro. Acta Biomater 41: 100-109.

Yun YR, Won JE, Jeon E, Lee S, Kang W, Jo H, Jang JH, Shin US, Kim HW (2010) Fibroblast growth factors: biology, function, and application for tissue regeneration. J Tissue Eng: 218142.

Zhang J, Wang JH-C (2010) Characterization of differential properties of rabbit tendon stem cells and tenocytes. BMC Musculoskelet Disord 11: 10-21.

Zhao X, Hadjiargyrou M (2011) Induction of cell migration in vitro by an electrospun PDGF-BB/
PLGA/PEG-PLA nanofibrous scaffold. J Biomed Nanotechnol 7: 823-829.

Zhou Z, Akinbiyi T, Xu L, Ramcharan M, Leong DJ, Ros SJ, Colvin AC, Schaffler MB, Majeska RJ, Flatow EL, Sun HB (2010) Tendon-derived stem/ progenitor cell aging: defective self-renewal and altered fate. Aging Cell 9: 911-915.

Zisch AH, Lutolf MP, Hubbell JA (2003) Biopolymeric delivery matrices for angiogenic growth factors. Cardiovasc Pathol 12: 295-310.

Ziyadeh N, Fife D, Walker AM, Wilkinson GS, Seeger JD (2011) A matched cohort study of the risk of cancer in users of becaplermin. Adv Skin Wound Care 24: 31-39.

\section{Discussion with Reviewer}

Denitsa Docheva: How do the authors foresee the integration of PDGF-BB delivery devices, such as electrospinned polymers, once the healing process has been activated and the initial granulation tissue has been formed?

Authors: The way of PDGF-BB application one week after the operation is not meant to be performed by reopening the wound and manipulating for a second time. In contrast, delivery devices releasing the largest amount of PDGF-BB one week after the operation are desired systems. Partial degradation of the delivery device after the initial week should lead to highest PDGF-BB release at that point, as mentioned in "Current limitations and future work" paragraph.

On the other hand, the in vivo performance of the delivery device, e.g. electrospun scaffolds, should be considered at the starting point, even before incorporating a growth factor. Careful and comprehensive degradation and integration studies of the devices must precede any further investigation. Cell infiltration and biomaterial encapsulation is how the integration of the electrospun scaffolds usually takes place and with time, if biodegradable, the material is degraded and reabsorbed.

Our research group has used the polymer DegraPol $^{\circledR}$ as a drug delivery device. As a first step, we investigated the effects in terms of in vivo cellular response towards this foreign material and focused on its integration. We found that it was very well accepted and no further inflammatory response was found. Moreover, in vivo, after 12 weeks, the degradation products were well integrated and penetrated by invading cells (Buschmann et al., 2013; Buschmann et al., 2015).

Editor's note: The Scientific Editor responsible for this paper was Juerg Gasser. 